\title{
From behavioral context to receptors: serotonergic modulatory pathways in the IC
}

\author{
Laura M. Hurley* and Megan R. Sullivan \\ Department of Biology, Center for the Integrative Study of Animal Behavior, Indiana University, Bloomington, IN, USA
}

\section{Edited by:}

Manuel S. Malmierca, University

of Salamanca, Spain

Reviewed by:

Michael R. Burger, Lehigh

University, USA

Wilhelmina Mulders, University of

Western Australia, Australia

\section{*Correspondence:}

Laura M. Hurley, Department of

Biology, Indiana University, 1001 E.

Third St., Bloomington, IN 47405,

USA.

e-mail: Ihurley@indiana.edu
In addition to ascending, descending, and lateral auditory projections, inputs extrinsic to the auditory system also influence neural processing in the inferior colliculus (IC). These types of inputs often have an important role in signaling salient factors such as behavioral context or internal state. One route for such extrinsic information is through centralized neuromodulatory networks like the serotonergic system. Serotonergic inputs to the IC originate from centralized raphe nuclei, release serotonin in the IC, and activate serotonin receptors expressed by auditory neurons. Different types of serotonin receptors act as parallel pathways regulating specific features of circuitry within the IC. This results from variation in subcellular localizations and effector pathways of different receptors, which consequently influence auditory responses in distinct ways. Serotonin receptors may regulate GABAergic inhibition, influence response gain, alter spike timing, or have effects that are dependent on the level of activity. Serotonin receptor types additionally interact in nonadditive ways to produce distinct combinatorial effects. This array of effects of serotonin is likely to depend on behavioral context, since the levels of serotonin in the IC transiently increase during behavioral events including stressful situations and social interaction. These studies support a broad model of serotonin receptors as a link between behavioral context and reconfiguration of circuitry in the $\mathrm{IC}$, and the resulting possibility that plasticity at the level of specific receptor types could alter the relationship between context and circuit function.

Keywords: serotonin, receptor, 5-HT1A, 5-HT1B, 5-HT2, 5-HT3, behavioral context

\section{INTRODUCTION}

The convergence of ascending, descending, and lateral circuitry in the inferior colliculus (IC) creates neural response properties important for decoding specific features of the auditory scene (Huffman and Henson, 1990; Vater et al., 1995; Kidd and Kelly, 1996; Thompson and Schofield, 2000; Malmierca et al., 2005a,b, 2009; Schofield and Coomes, 2006; Winer, 2006; Yavuzoglu et al., 2010; Oertel et al., 2011; Yavuzoglu et al., 2011). To build circuits that respond to changing behavioral contexts, information that is extrinsic to the auditory system must also be incorporated into this convergence. Inputs signaling behavioral context or internal state strongly influence the responses of neurons in the IC to auditory stimuli. For example, external cues indicating the presence of a social partner, or internal signals of stress or reproductive state, can alter evoked responses or gene expression in the IC and its homologs in nonmammalian vertebrates (Mello and Ribeiro, 1998; Miranda and Wilczynski, 2009a,b; Mazurek et al., 2010; Mangiamele and Burmeister, 2011). There are numerous mechanisms through which extra-auditory sources

\footnotetext{
Abbreviations: 8-OH-DPAT, 8-Hydroxy-2-(di-n-propylamino)tetralin; CP93129, 3-(1,2,3,6-tetrahydropyridin-4-yl)-1,4-dihydropyrrolo[3,2-b]pyridin-5one; DNLL, dorsal nucleus of the lateral lemniscus; DOI, 2,5-dimethoxy-4iodoamphetamine; DRN, nucleus raphe dorsalis; IC, inferior colliculus; MK212, 2-Chloro-6-(1-piperazinyl)pyrazine; $\mathrm{mCPBG}, \mathrm{m}$-chlorophenylbiguanidine; $\mathrm{pCPA}$, parachlorophenylalanine; SERT, serotonin transporter; SSRI, selective serotonin reuptake inhibitor.
}

of information influence neural processing in the IC, including input pathways from visual and somatosensory systems or pathways from affective centers such as the amygdala (Groh et al., 2001; Marsh et al., 2002; Metzger et al., 2006; Zhou and Shore, 2006; Dehmel et al., 2008). Hormonal pathways (Greco et al., 1999; Charitidi and Canlon, 2010; Maney and Pinaud, 2011) and centralized neurochemical pathways (Levitt and Moore, 1979; Klepper and Herbert, 1991; Thompson et al., 1994; Habbicht and Vater, 1996; Wynne and Robertson, 1996; Kaiser and Covey, 1997; Tong et al., 2005; Ji and Suga, 2009; Motts and Schofield, 2009, 2011) also provide potential routes for nonauditory signals.

Neuromodulatory networks comprise a large class of mechanisms linking behavioral context and internal state to local changes in auditory processing within the IC. Multiple neuromodulators including norepinephrine, acetylcholine, serotonin, and dopamine are present in the IC (Levitt and Moore, 1979; Klepper and Herbert, 1991; Thompson et al., 1994; Habbicht and Vater, 1996; Wynne and Robertson, 1996; Kaiser and Covey, 1997; Tong et al., 2005; Ji and Suga, 2009; Motts and Schofield, 2009, 2011). Neurons synthesizing these modulatory signals typically respond to salient features of behavioral situations and communicate this information to the IC through axonal projections that may ramify widely in the IC and other regions of the central nervous system. Although in some cases auditory neurons contain these neurochemicals, they can also be found in centralized extra-auditory nuclei (Klepper and Herbert, 1991; Tong et al., 
2005; Motts and Schofield, 2009). Neuromodulatory systems have the ability to profoundly alter auditory processing in the IC, facilitating signatures of associative and other types of plasticity, or altering excitatory-inhibitory interactions to change ongoing responses to stimuli (Farley et al., 1983; Habbicht and Vater, 1996; Yigit et al., 2003; Hurley et al., 2004; Ji and Suga, 2009).

This review will focus on how the serotonergic neuromodulatory system in particular alters the function of circuits in the IC. The first reason for this focus is that the serotonergic system is unambiguously extrinsic to the auditory system in adults (Klepper and Herbert, 1991; Thompson and Lauder, 2005; Thompson, 2006; Thompson and Thompson, 2009). The serotonergic system is thus a clear candidate source of nonauditory information to the IC. Second, the serotonergic system is potentially a conduit for several major classes of nonauditory information to the IC, including information on the sleep-wake cycle, stress, and social encounters or social status (Boutelle et al., 1990; Mas et al., 1995; Clement et al., 1998; Jacobs and Fornal, 1999; Portas et al., 2000). Lastly, serotonin strongly modulates the sound-evoked activity of IC neurons (Hurley and Pollak, 1999, 2001; Hurley et al., 2002).

\section{SOURCES OF SEROTONIN ARE EXTRINSIC TO THE IC}

Serotonergic innervation of the IC has been noted for decades. In adults, no auditory neurons contain serotonin, although during development neurons in some brainstem auditory nuclei are transiently immunopositive for the serotonin transporter (SERT) and accumulate serotonin (Thompson and Lauder, 2005; Thompson, 2006; Thompson and Thompson, 2009). Dense innervation of the auditory midbrain by serotonergic fibers is conserved across vertebrate groups, as is the relative density of fibers in different subnuclei (Figure 1; Klepper and Herbert, 1991; Kaiser and Covey, 1997; Zeng et al., 2007). Fibers are denser in shell regions such as the dorsal and external cortices, something that has been confirmed quantitatively (Klepper and Herbert, 1991; Thompson et al., 1994; Kaiser and Covey, 1997; Hurley and Thompson, 2001; Zeng et al., 2007; Matragrano et al., 2012; Papesh and Hurley, 2012). Although serotonergic projections are somewhat denser in cortical IC regions, substantial innervation by serotonergic fibers also occurs in the central subnucleus (Papesh and Hurley, 2012). Once released, serotonin may act either synaptically or extrasynaptically in some brain regions in a process known as volume release (Bunin and Wightman, 1999). A synaptic morphology suggestive of nonsynaptic release has been described for specialized serotonergic "basket terminals" found around a subset of GABAergic neurons in primary auditory cortex of cat (Defelipe et al., 1991). The structure of serotonergic release sites has not been explored in the IC, however.

The major source of serotonergic fibers to the IC is the dorsal raphe nucleus (DRN), a superior nucleus in a chain of serotoninproducing raphe nuclei in the vertebrate brain. Approximately $80 \%$ of raphe neurons that both contain an IC-injected retrograde tracer and co-label with an antibody to serotonin are found in the DRN, with smaller proportions found in other regions such as the median raphe nucleus (14\%) (Klepper and Herbert, 1991). Beyond this simple characterization, little information is available regarding the significance of anatomical relationships between the raphe nuclei and the IC. For example, whether subgroups of DRN neurons disproportionately innervate the IC has not been established.

\section{THE SEROTONERGIC SYSTEM PROVIDES INFORMATION ON EXTERNAL EVENTS AND INTERNAL STATE TO THE IC}

Supporting the concept that the anatomical connection between the DRN and IC serves as a conduit for multiple types of nonauditory information into the IC, the DRN itself receives inputs from many other brain regions. These include relatively peripheral sensory areas such as the retina, vestibular nuclei, and purported multisensory regions that likely process sound (Kawano et al., 1996; Ye and Kim, 2001; Cuccurazzu and Halberstadt, 2008). They also include regions such as amygdala, preoptic areas, and prefrontal cortex (Peyron et al., 1998; Lee et al., 2003). As a consequence of these projections, the activity of DRN neurons is influenced by a wide range of behaviorally relevant factors. The tonic level of activity of DRN neurons depends heavily on the phase of the sleep-wake cycle, with firing rates higher in waking states. DRN neurons also respond transiently to simple sensory stimuli (Heym et al., 1982; Jacobs and Fornal, 1999), and follow

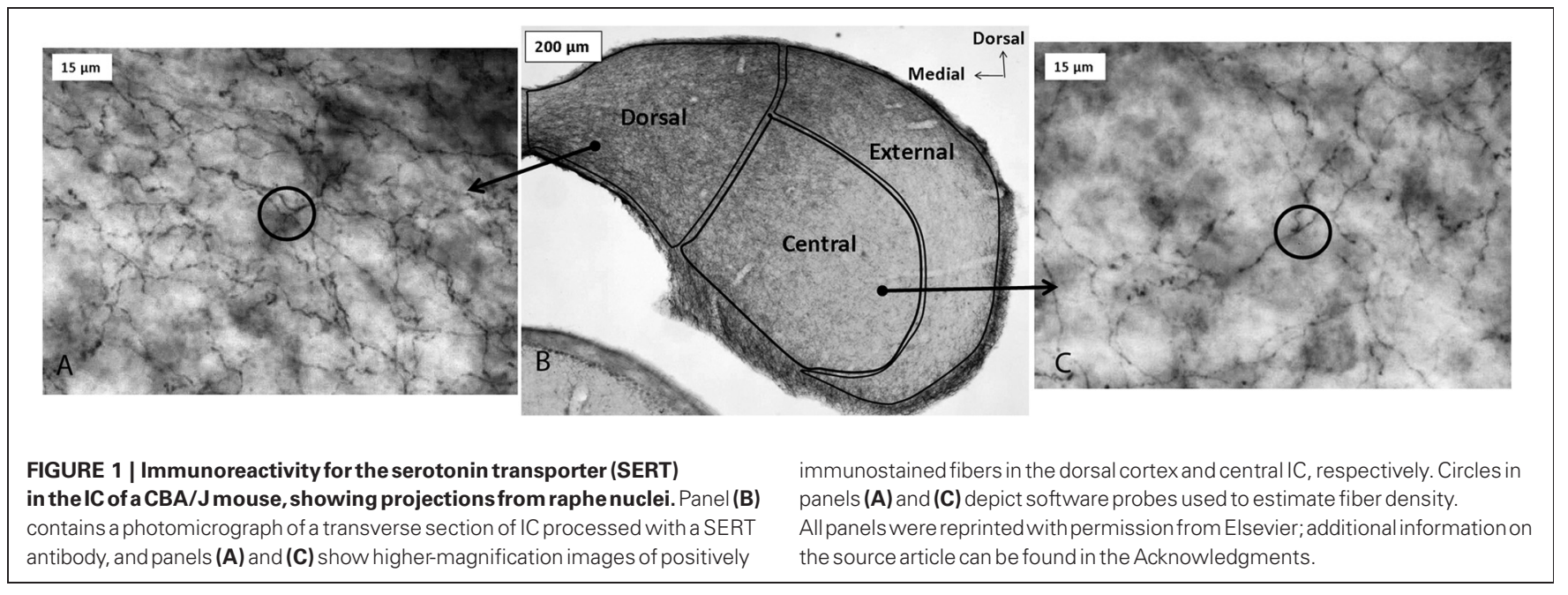


higher-level features of behavioral paradigms such as the delay of a reward (Miyazaki et al., 2011).

There is also direct evidence that both behavioral state and the occurrence of external events regulate serotonin levels within the IC (Figure 2; reviewed in Hurley and Hall, 2011). As expected from the influence of the sleep/wake cycle on activity in the DRN, locally measured serotonin in the IC increases as mice wake from anesthesia (Hall et al., 2010). On top of this tonic change, serotonin increases within minutes in the IC in response to loud broadband noise and to restriction stress, but not to other simple stimuli that evoke strong behavioral responses such as the presentation of food or odor of a predator (Hall et al., 2010). Serotonin also increases in the IC over the course of social interactions including same-sex resident-intruder interactions (Hall et al., 2011) and opposite-sex encounters (unpublished data). The dynamics of serotonergic increases are distinct across different types of behavioral paradigms, such that increases during social interactions are more gradual than during the presentation of simple stressors (Hurley and Hall, 2011).

\section{SEROTONIN STRONGLY MODULATES AUDITORY RESPONSES IN THE IC}

The local application of exogenous serotonin and the release of local stores of serotonin have strong effects on the auditory responses of single IC neurons, supporting the idea that context-specific changes in serotonin have functional consequences (Hurley and Pollak, 1999; Hall and Hurley, 2007). A prominent effect of serotonin is to control the gain of IC responses across the frequency tuning curve. In most cases, serotonin suppresses responses evoked by tones and FM sweeps, but in a minority of neurons, serotonin facilitates responses (Hurley and Pollak, 1999, 2001). Among the more interesting effects of serotonin observed in a subset of IC neurons are frequency-specific changes in firing rate. For these neurons, serotonin may strongly suppress or facilitate responses to tones at some frequencies, but leave responses to other frequencies in the tuning curve relatively unaffected (Hurley and Pollak, 2001). Either uniform gain control or frequency-specific effects can result in changes in the bandwidths of frequency response ranges (Hurley and Pollak, 2001). Such changes in tuning further result in changes in the selectivity of neurons for more complex sounds.

Not surprisingly, the pronounced changes in spike rate induced by serotonin are often accompanied by changes in multiple temporal features of spike trains, including initial spike latency and variance, interspike interval (ISI), and the response durations of IC neurons (Hurley and Pollak, 2005b). Changes in temporal response properties such as the initial spike latency often correspond to changes in spike rate, so that spike suppression is associated with increased latency, and spike facilitation with decreased latency, but can also occur independently of changes in spike rate. In addition to changing temporal response properties of IC neurons, serotonin also targets neurons with particular temporal characteristics. Across multiple studies, neurons with latencies of over approximately $10 \mathrm{~ms}$, or with relatively low firstspike precision, show greater sensitivity to serotonergic agonists including serotonin, a 5-HT1A agonist, and a 5-HT3 agonist (Hurley and Pollak, 2005b; Hurley, 2007; Bohorquez and Hurley,

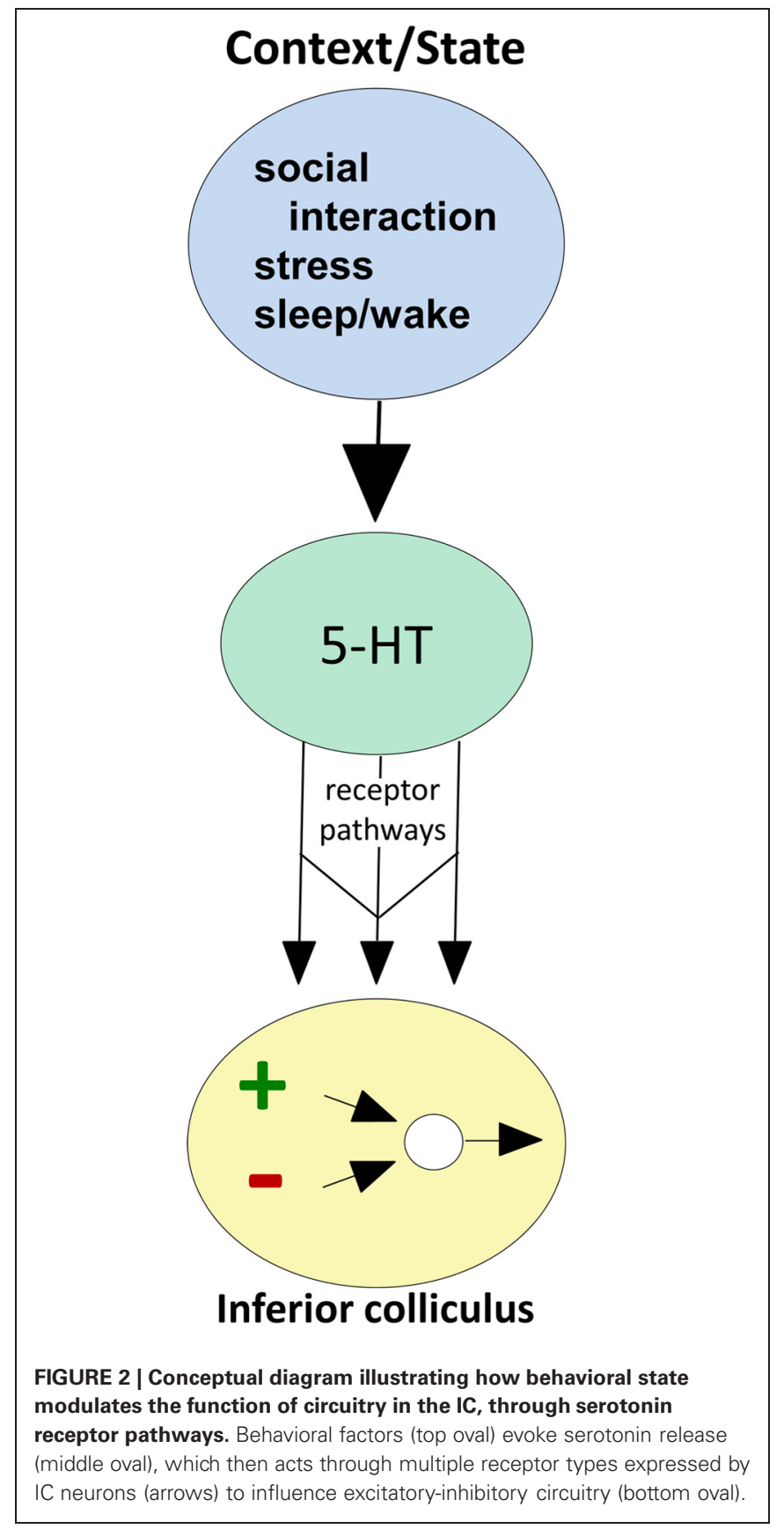

2009). These consistent findings suggest that longer-latency or lower-precision neurons either preferentially express some types of serotonin receptors or are more responsive to activation of these receptors. Interestingly, IC neurons with latencies of over $12 \mathrm{~ms}$ are also more reliably sensitive to NMDA receptor blockade and less sensitive to AMPA receptor blockade (Sanchez et al., 2007). Together, these studies hint at the existence of distinct sets of neurochemical sensitivities in groups of IC neurons defined by their temporal characteristics.

Studies at the level of single IC neurons thus illustrate that serotonin and its receptors are capable of broadly reshaping temporal features of evoked activity in the IC. In agreement 
with this hypothesis, brain-wide depletion of serotonin using parachlorophenylalanine ( $\mathrm{pCPA}$ ) alters the latencies of auditory brainstem response (ABR) waves including wave $\mathrm{V}$, which is likely to be influenced by activity in the IC (Funai and Funasaka, 1983; Kaga et al., 1999). The effect of pCPA may depend on the species under study or on stimulus parameters such as repetition rate, since the same type of serotonergic depletion has been reported to either decrease or increase ABR latencies (Revelis et al., 1998). Taken as a whole, however, these findings underscore the global effects of the manipulation of endogenous sources of serotonin on the timing of auditory activity.

\section{SEROTONIN RECEPTOR TYPES DEFINE PARALLEL PATHWAYS FOR REGULATION OF IC CIRCUITRY}

The strength and dynamics of the effects of endogenously released serotonin are regulated by local mechanisms in the IC, including high-affinity transporters expressed by serotonergic projections as well as lower-affinity organic cation transporters (Hoffman et al., 1998; Gasser et al., 2009; Hall et al., 2010). A particularly important aspect of local regulation of serotonergic effects is the expression of serotonin receptors by auditory neurons in the IC (Thompson et al., 1994; Hurley, 2006). Of all the classes of molecules regulating serotonergic signaling locally, different types of serotonin receptor have the most potential to provide insight into the wide range of serotonergic effects on IC neurons. This is because receptors are differentially expressed by IC neurons, and different receptor types have highly characteristic effector pathways and patterns of subcellular localization (Hannon and Hoyer, 2008). This diversity creates a wide range of potential neuromodulatory effects that are quite specific for the auditory circuitry of the IC, even though they originate from a diffusely projecting neurochemical system. Different serotonin receptor types therefore act as parallel pathways for altering specific features of circuitry in the IC (Figure 2).

Different serotonin receptor types represent an especially rich source of potential functional variability relative to receptors of other types of neuromodulators, because of the exceptionally wide array of serotonin receptor types. There are seven major families of serotonin receptors, several of which include multiple well-characterized and functionally distinct members (Hannon and Hoyer, 2008). Most of these families consist of G-protein coupled receptors. 5-HT3 receptors are the exception, and are cation channels similar in structure to nicotinic acetylcholine receptors (Chameau and Van Hooft, 2006). Consistent with this predominantly metabotropic set of effector pathways, the actions of serotonin receptors in the IC conform to classical models of neuromodulator function. That is, rather than directly creating responses to auditory stimuli, serotonin receptors reconfigure auditory circuits mediated by other neurotransmitters (HarrisWarrick, 2011). Although members of at least five families of serotonin receptor have been reported in the IC, members of only three of these have been explored in terms of their physiological function: 5-HT1, 5-HT2, and 5-HT3 receptors (Chalmers and Watson, 1991; Pompeiano et al., 1992; Thompson et al., 1994; To et al., 1995; Wright et al., 1995; Waeber et al., 1996; Morales and Bloom, 1997; Peruzzi and Dut, 2004; Hurley, 2006; Wang et al., 2008; Bohorquez and Hurley, 2009; Miko and Sanes, 2009).
Multiple studies on the function of specific serotonin receptor types in the IC have used the approach of extracellular recording of sound-evoked responses in vivo during the local iontophoresis of serotonin receptor agonists and antagonists (Figure 3; Hurley and Pollak, 1999, 2001, 2005a,b; Hurley, 2006, 2007; Hurley et al., 2008; Bohorquez and Hurley, 2009; Ramsey et al., 2010). In these types of studies, inferences on the influence of serotonin receptor types on particular features of the circuitry of the IC are based on three types of information: the demonstrated cellular mechanisms of these receptors throughout the brain, their specific effects in the IC, and their interaction with neurotransmitter systems in the IC. With several important exceptions that are described below, the cellular mechanisms of serotonergic action in the IC are therefore largely unexplored through in vitro recording techniques. In the remainder of this section, we present direct and indirect evidence supporting roles for specific serotonin receptor pathways in the modulation of inhibition, the suppression of responsiveness to input, and the mediation of activity-dependent plasticity. The interaction of some serotonin receptor types is also described.

\section{SEROTONERGIC MODULATION OF INHIBITION}

The IC contains a strong inhibitory network and excitatoryinhibitory balance is particularly important for acoustic processing in the IC (Yang et al., 1992; Casseday et al., 1994; Fuzessery and Hall, 1996; Lebeau et al., 1996; Casseday et al., 2000). Serotonergic modulation of inhibition is one type of mechanism that shifts the excitatory-inhibitory balance and selectively tunes sensory processing (Ciranna, 2006). GABA is a major inhibitory neurotransmitter in the IC and activates two types of receptors, $\mathrm{GABA}_{\mathrm{A}}$ and $\mathrm{GABA}_{\mathrm{B}}$ receptors (Wisden et al., 1992; Fubara et al., 1996). $\mathrm{GABA}_{A}$ receptors directly pass $\mathrm{Cl}^{-}$and have modulatory binding sites for benzodiazepines, barbiturates, neurosteroids, and ethanol (Macdonald and Olsen, 1994). In contrast, GABA receptors couple to $\mathrm{Ca}^{2+}$ and $\mathrm{K}^{+}$channels via $\mathrm{G}$ proteins and second messengers (Bowery, 1989). Serotonergic inputs could also potentially modulate glycinergic inhibitory transmission, but there is currently little data on the effects of serotonin on glycinergic inhibition in the IC or other brain areas (Engelhardt et al., 2010). For this reason, we will focus on serotonergic modulation of GABAergic transmission by describing (1) the anatomical association between the serotonergic and GABAergic systems, and (2) the modulation of GABAergic transmission by serotonin.

\section{Anatomical association between 5-HT receptors and inhibitory interneurons}

The serotonergic nucleus providing most of the serotonergic fibers to the IC, the DRN, has a distinct relationship with GABAergic neurons in other brain regions that provides a useful comparison for the IC. In the hippocampus and cortex, selective serotonergic modulation of inhibitory neurons has been observed (Freund et al., 1990; Defelipe et al., 1991). In particular, the serotonergic raphe-hippocampal pathway forms multiple synaptic contacts with calbindin D-28k-containing GABAergic interneurons, but not parvalbumin-expressing GABAergic interneurons (Freund et al., 1990). Both calbindin and parvalbumin are calcium binding proteins usually located in inhibitory interneurons. 

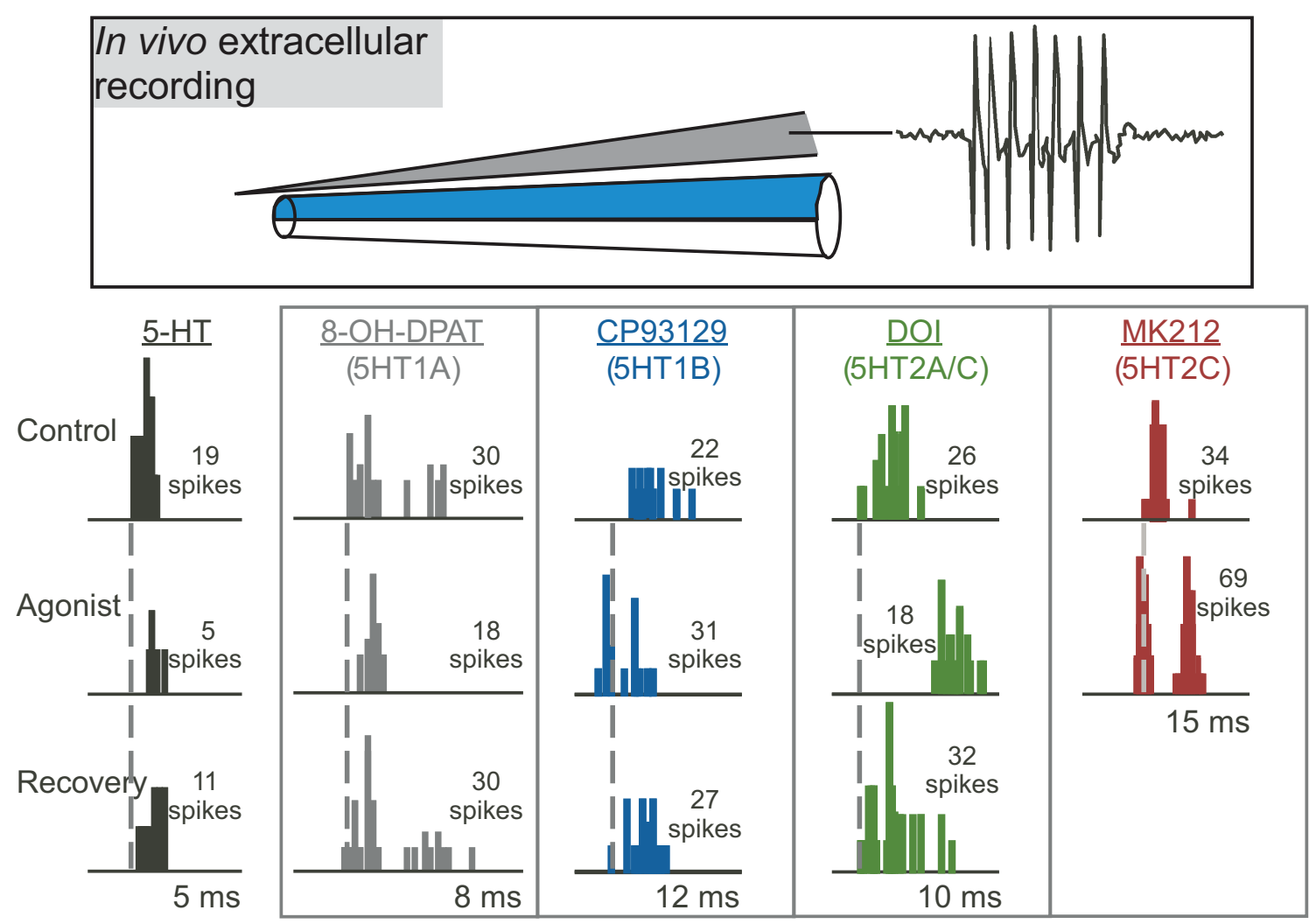

FIGURE 3 | Effects of different serotonin (5-HT) receptor agonists on spike number and latency in response to 32 repetitions of a tone at characteristic frequency. The top panel depicts a "piggyback" electrode used for combined extracellular recording of single neurons and drug iontophoresis. The lower panel shows PSTHs of responses in the control, during the iontophoresis of agonists, and in the recovery are shown for five different sample neurons in the IC. Specific agonists and the receptors they target appear above each neuron. Dashed vertical lines mark the latencies of the earliest spikes in the control condition. Stimuli were: for serotonin, a 10-kHz FM sweep centered at $25 \mathrm{kHz}$ at $20 \mathrm{~dB} \mathrm{SPL}$; for 8-OH-DPAT, a 10-kHz FM sweep centered at $25 \mathrm{kHz}$ at $40 \mathrm{~dB} \mathrm{SPL}$; for CP93129, a 20-kHz tone at $20 \mathrm{~dB}$ SPL; for DOI, a 7-kHz FM sweep centered at $21 \mathrm{kHz}$ at $50 \mathrm{~dB}$ SPL; for MK212, a $5-\mathrm{kHz}$ FM sweep centered at $19 \mathrm{kHz}$ at $50 \mathrm{~dB}$ SPL. All stimuli were $10 \mathrm{~ms}$ in duration. The lower panel was reprinted from a journal published by the American Physiological Society; additional information on the source article can be found in the Acknowledgments.
This suggests that the serotonergic pathway may influence synaptic function through modulation of local inhibitory circuits. Similar anatomical targeting of projections from the DRN onto GABAergic neurons has been observed around somata and dendrites of GABAergic neurons in primary auditory cortex (Defelipe et al., 1991). In other cortical areas, inhibitory interneurons have also been identified as major targets of serotonergic synapses (Smiley and Goldmanrakic, 1996). This input specificity from raphe axons suggests a modulatory diversity in inhibitory cell types.

In the IC, it is not known whether serotonergic inputs to the IC target specific inhibitory neuron cell types as observed in the hippocampus and cortex. However, staining for both calbindin and parvalbumin, which label neuronal cell types targeted by raphe projections in the hippocampus and cortex, is localized to the superficial rim of the external cortex and dorsal cortex and is almost completely absent from the central nucleus (Celio, 1990; Lohmann and Friauf, 1996). To some extent, the distribution of these presumptive inhibitory interneurons therefore parallels the density of serotonergic fibers in the subregions of the IC.
In addition to targeting at the level of serotonergic projections, there is evidence for anatomical segregation of serotonergic effects based on the selective expression of serotonin receptors by different cell types (Jakab and Goldman-Rakic, 2000). In cortical neurons, 5-HT2A receptors are segregated from 5-HT3 receptors. 5-HT2A receptors are found in pyramidal neurons and in GABAergic interneurons expressing parvalbumin and calbindin. 5-HT3 receptors are found in small GABAergic interneurons with calbindin and medium calretinin-containing interneurons (Morales and Bloom, 1997; Jakab and Goldman-Rakic, 2000). This cellular segregation indicates a serotonin-receptor specific segmentation of the GABAergic inhibitory actions along the pyramidal neuronal arbor (Jakab and Goldman-Rakic, 2000).

There is some evidence for the expression of serotonin receptor types by GABAergic neurons in the IC. Approximately two-thirds of GABA-positive neurons are associated with 5-HT1A or 5$\mathrm{HT} 1 \mathrm{~B}$ receptors, with neurons positive for $5 \mathrm{HT} 1 \mathrm{~B}$ receptors more numerous than neurons positive for 5HT1A receptors (Peruzzi and Dut, 2004). GABAergic neurons in the IC can additionally be subdivided into at least two groups based on soma size and their innervation by different types of glutamatergic terminals 
(Ito et al., 2009), but whether serotonin differentially regulates these neural classes is unknown. This association between serotonin receptors and GABAergic neurons provides some suggestive evidence that serotonergic modulation may target the inhibitory network in the IC, similar to mechanisms in other brain regions (Peruzzi and Dut, 2004).

It is essential to note that IC neurons receive GABAergic inputs from a range of sources. The dorsal nucleus of the lateral lemniscus (DNLL) sends a bilateral GABAergic projection to IC that shapes binaural responses (Adams and Mugnaini, 1984; Shneiderman et al., 1988; Shneiderman and Oliver, 1989; Faingold et al., 1993; Shneiderman et al., 1993; Burger and Pollak, 2001; Pollak et al., 2002), and other nuclei of the lateral lemniscus also contain GABAergic neurons that project to IC (Zhang et al., 1998). GABAergic projections to IC also arise from neurons in the contralateral IC (Gonzalez-Hernandez et al., 1996; Hernandez et al., 2006). Small numbers of GABAergic neurons project to the IC from periolivary regions and cochlear nuclei (GonzalezHernandez et al., 1996). IC neurons also receive projections from intrinsic GABAergic neurons, which constitute a substantial proportion of cell bodies in the IC (Roberts and Ribak, 1987; Oliver et al., 1994). Which of these populations of GABAergic neurons are modulated by the $5-\mathrm{HT} 1 \mathrm{~B}$ and $5-\mathrm{HT} 2 \mathrm{~A}$ receptors has not yet been explored, but this information could provide an important clue as to the functional consequences of the modulation of inhibition by serotonin receptors.

\section{Modulation of GABAergic inhibition}

Multiple studies have explored the functional interaction between serotonin receptors and GABAergic inhibition. In vitro evidence from one study suggests that the 5-HT2A receptor modulates GABAergic inhibition in the IC (Wang et al., 2008). In this study, serotonin enhanced the frequency and amplitude of spontaneous inhibitory postsynaptic currents (sIPSCs) in $70 \%$ of neurons recorded. A selective 5-HT2A agonist ( $\alpha$ methylserotonin) mimicked the effect of serotonin on sIPSCS. The observation of enhanced sIPSCs in the IC is consistent with data from other brain regions including the substantia nigra (Stanford and Lacey, 1996) and cortex (Zhou and Hablitz, 1999).

Additional support for a role of the 5-HT2 receptor dependent modulation of inhibition in the lateral superior olive (LSO) is supported by a series of experiments using whole cell voltageclamp recordings of gerbil slices from postnatal days 6-13 (Fitzgerald and Sanes, 1999). These experiments identified an increase in spontaneous inhibitory postsynaptic currents (IPSCs) with the application of 5-HT. Upon further examination, a 5-HT2 agonist $(\alpha-\mathrm{Me}-5-\mathrm{HT})$ reproduced the increase in spontaneous IPSCs and a 5-HT2 antagonist (ketanserin) blocked the induction of spontaneous IPSCs. This specific modulation of inhibition by the 5-HT2 receptor was developmentally dependent and generally not observed beyond postnatal day 8. It is not yet known if a similar developmentally dependent mechanism of serotonergic modulation might be observed in the IC or other regions in the auditory pathway.

Another type of serotonin receptor, the 5-HT1B receptor, may also affect GABAergic transmission. Activation of this receptor type strongly facilitates sound-evoked responses (Hurley, 2006). In other brain regions, the 5-HT1B receptor is localized to presynaptic axons or terminals and decreases the release of a range of neurotransmitters (Sari, 2004). These facts underlie the hypothesis that the $5-\mathrm{HT} 1 \mathrm{~B}$ receptor decreases the release of inhibitory neurotransmitter in the IC. An in vivo study examined whether the 5-HT1B receptor influences responses to GABAergic inhibition in the IC by using the selective 5HT1B agonist CP93129 in combination with the co-application of $\mathrm{GABA}_{\mathrm{A}}$ receptor antagonists (bicuculline or gabazine; Figure 4).

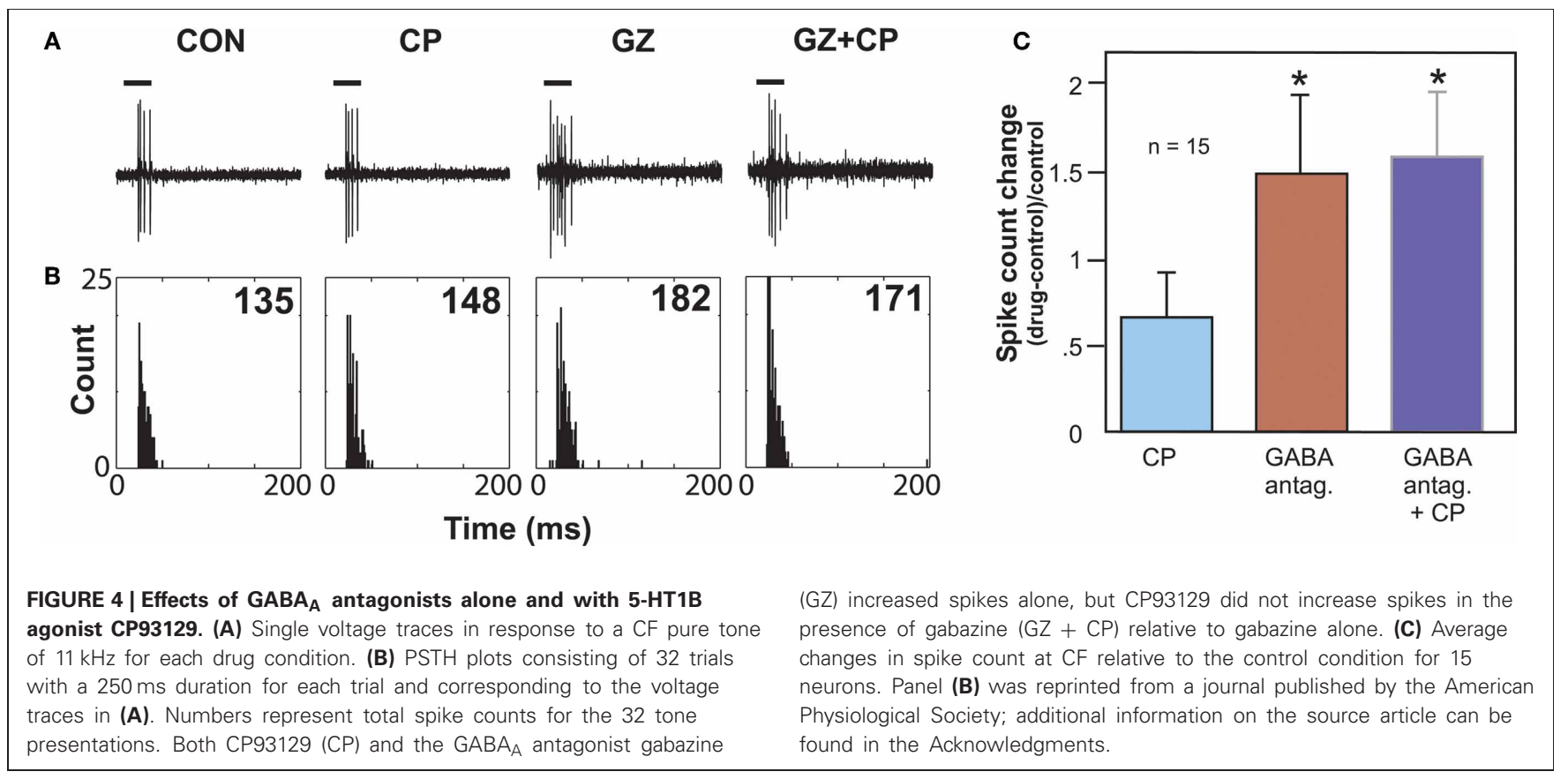


This combination tested the prediction that 5-HT1B activation and blockade of GABAergic inhibition would create similar effects. Indeed, 5-HT1B activation and $\mathrm{GABA}_{\mathrm{A}}$ blockage, when each manipulation was performed alone, had similar effects on the direction and magnitude of responses, frequency response bandwidths, and ISIs, although the effects of GABA blockade were typically larger. Furthermore, following the increase in spike number induced by $\mathrm{GABA}_{\mathrm{A}}$ receptor antagonists alone, the addition of a 5-HT1B agonist did not cause a further facilitation, suggesting that blockage of $\mathrm{GABA}_{\mathrm{A}}$ receptors reduced the effect of activating 5-HT1B receptors (Hurley et al., 2008). Taken together with the localization of 5-HT1B receptors to presynaptic axons or terminals in other brain regions, these experiments provide evidence for modulation of GABAergic inhibition in the IC by the 5-HT1B receptor.

Multiple authors have found that GABAergic inhibition surrounding the characteristic frequencies of IC neurons sharpens frequency tuning (Yang et al., 1992; Fuzessery and Hall, 1996; Palombi and Caspary, 1996; Lebeau et al., 2001; Lu and Jen, 2001). A functional test of whether the 5 -HT1B receptor regulates excitatory-inhibitory balance in these frequency regions was performed in vivo by suppressing the excitatory responses to a tone at the characteristic frequency with the co-presentation of tones at surrounding frequencies (Hurley et al., 2008). The effect of a 5-HT1B selective agonist (CP93129) on the excitatory-inhibitory balance was then tested using such two-tone stimuli. The 5-HT1B agonist often decreased the suppression of the tone at characteristic frequency by tones at surrounding frequencies (Hurley et al., 2008). The 5-HT1B agonist also expanded frequency tuning in many neurons, and in some cases the frequencies of expansion corresponded to frequencies at which reduction of suppression occurred. This suggests that the $5-\mathrm{HT} 1 \mathrm{~B}$ receptor regulates the sharpness of frequency tuning in some IC neurons by reducing surround inhibition.

All of the studies described above indicate that GABAergic inhibition in the IC is regulated by multiple types of serotonin receptor, which influence GABAergic transmission in different ways.

\section{SUPPRESSION OF RESPONSES BY SEROTONIN}

A common effect of applying serotonin is the suppression, or decrease in magnitude, of evoked responses and spontaneous activity in IC neurons (Hurley and Pollak, 1999). Suppression by serotonin could be achieved through multiple serotonin receptor types and through pre- and postsynaptic mechanisms. The 5-HT1A receptor is likely to be one of the receptors, if not the predominant receptor, mediating suppression of responses. The expression of the 5-HT1A receptor is widespread throughout the IC including expression in inhibitory neurons (Duncan et al., 1998; Peruzzi and Dut, 2004). The 5-HT1A receptor is often located somatodendritically and typically decreases postsynaptic responses through an association with inward-rectifying potassium channels (Okuhara and Beck, 1994; Polter and Li, 2010).

Experiments in the IC of the mouse and Mexican free-tailed bat have shown that a 5-HT1A receptor agonist (8-OH-DPAT) suppress responses and shifts the temporal response profile to pure tones and FM sweeps (Figure 5; Hurley, 2006, 2007).

\section{A Spike count decrease}

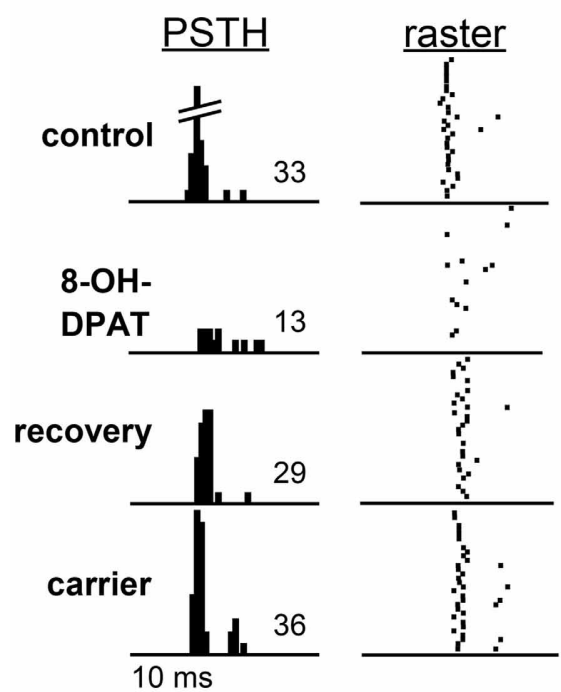

FIGURE 5 | Effects of the selective 5-HT1A agonist 8-OH-DPAT on a single neuron (A) and on a population of IC neurons (B). (A) PSTH and raster plots of the response of a neuron to an FM sweep in the control, during iontophoresis of 8-OH-DPAT, during the recovery, and during the iontophoresis of the carrier solution. The stimulus was a $30-\mathrm{dB} \mathrm{SPL}, 10-\mathrm{kHz}$ FM sweep centered at $25 \mathrm{kHz}$. (B) Histogram of changes in spike count

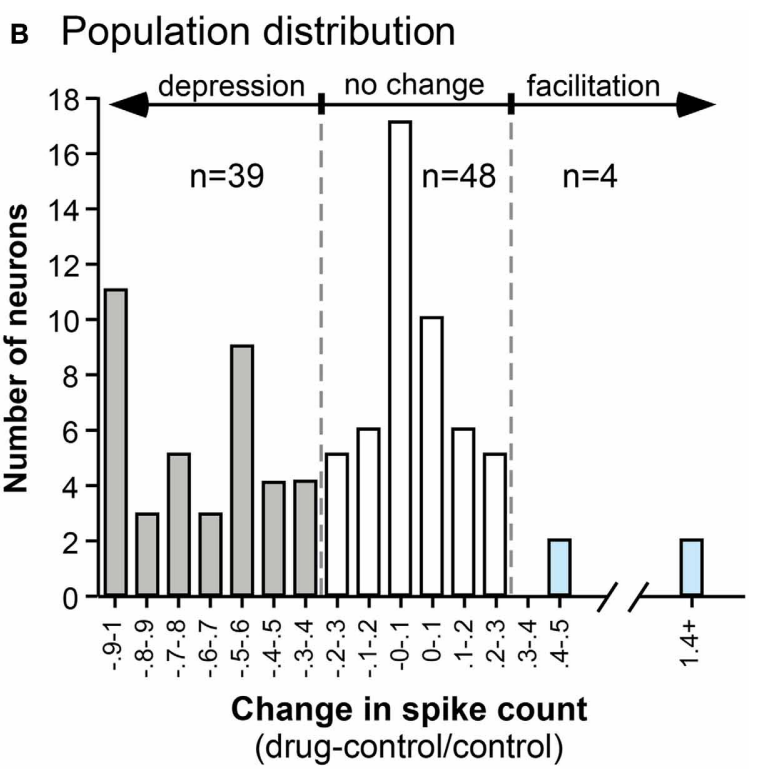

evoked by 8-OH-DPAT in 91 IC neurons. Negative values indicate decreases in spike count relative to the pre-drug control, and positive values indicate increases in spike count. Across the neuron population, the effect of 8-OH-DPAT is predominantly suppressive. All panels were reprinted with permission from Elsevier; additional information on the source article can be found in the Acknowledgments. 
5-HT1A activation often increases the first-spike latency and ISI, while differentially suppressing secondary spikes in IC neurons (Hall and Hurley, 2007; Ramsey et al., 2010). Interestingly, the 5-HT1A receptor agonist produces the effects most similar to applying serotonin alone when compared to agonists for 5-HT1B and 5-HT2C receptors, suggesting that the 5-HT1A receptor may play a comparatively strong role in serotonergic modulation (Hurley, 2006).

Similar to the diversity of effects of serotonin (Hurley and Pollak, 1999), selective activation of the 5-HT1A receptor results in facilitation in a small number of IC neurons (Hurley, 2006). The net result of 5-HT1A receptor-induced hyperpolarization may depend on whether the receptors are present on an excitatory or inhibitory neuron. With an excitatory neuron, the result would be a direct suppression of responses. However, with an inhibitory neuron, the result could be facilitation of the responses of postsynaptic neurons. In several brain regions, the 5-HT1A receptor has been demonstrated to alter presynaptic GABA release (Kishimoto et al., 2001; Lee et al., 2008). Additional experiments in the IC with 5-HT1A agonists and antagonists in combination with $\mathrm{GABA}_{\mathrm{A}}$ receptor antagonists (bicuculline or gabazine) will be required to determine the interactions between the 5-HT1A receptor and GABAergic inhibition in the IC.

A common consequence of suppression by the 5-HT1A receptor is a narrowing in the frequency tuning curves of the neurons. Functionally, response suppression may therefore serve to increase the selectivity of responses to auditory stimuli. This would provide an additional mechanism in addition to direct shifts in the inhibitory-excitatory synaptic balance for tuning of responses to auditory stimuli. A range of mechanisms, including suppression and inhibition, likely acts concurrently to result in behavioral context-related changes in the IC. Suppression based on postsynaptic hyperpolarization may provide an important mechanism for serotonergic-dependent tuning of auditory processing.

\section{SHORT-TERM PLASTICITY AND THE 5-HT3 RECEPTOR}

Of all serotonin receptor types in the IC, 5-HT3 receptors might be expected to mediate the most rapid and neurotransmitterlike effects. 5-HT3 receptors have a pentameric structure similar to that of nicotinic acetylcholine receptors (Chameau and Van Hooft, 2006). Also similar to AChRs, 5-HT3 receptors are cation channels that allow the passage of $\mathrm{Na}+$ and $\mathrm{Ca} 2+$ ions. Consistent with this mechanism of action, activation of 5-HT3 receptors does create rapid effects in some IC neurons, in seconds or less, comparable to application of neurotransmitters such as GABA and glutamate (Bohorquez and Hurley, 2009). For many IC neurons, however, the effects of activating the 5-HT3 receptor are much more slowly developing, with half-maximal effects occurring over a range from 10 to more than $150 \mathrm{~s}$, with correspondingly long recovery times. Furthermore, in a majority of 55\% of neurons that respond to a 5-HT3 agonist, the effects of 5-HT3 activation are suppressive rather than excitatory. One possible mechanism that could account for a suppressive effect of the 5-HT3 receptor is that it excites presynaptic inhibitory neurons such as GABAergic neurons (Shneiderman et al., 1993; Oliver et al., 1994; GonzalezHernandez et al., 1996; Zhang et al., 1998). GABAergic neurons are a target of the 5-HT3 receptor in other sensory systems, making this a plausible mechanism (Morales and Bloom, 1997; Xiang and Prince, 2003). This potential regulation of GABergic pathways by the 5-HT3 receptor was assessed in one study by comparing the effects of a 5-HT3 receptor agonist in the presence versus absence of a $\mathrm{GABA}_{\mathrm{A}}$ antagonist. The rationale behind this experiment was similar to that used for assessing whether the 5-HT1B receptor interacted with GABAergic transmission, with the logic that blocking $\mathrm{GABA}_{\mathrm{A}}$ receptors should reduce the effect of 5-HT3 activation, if the 5-HT3 receptor acts by increasing GABA release. Unlike the 5-HT1B receptor, the effect of 5-HT3 activation was not decreased and was even accentuated in some neurons in the presence of a $\mathrm{GABA}_{\mathrm{A}}$ antagonist (Bohorquez and Hurley, 2009). This finding led to rejection of the hypothesis that the 5-HT3 receptor suppresses evoked activity in many IC neurons by exciting presynaptic GABAergic neurons.

A second hypothesis that could account for the range of effects of the 5-HT3 receptor in the IC is that this receptor has a genuinely modulatory influence via the admission of calcium into IC neurons. An interesting comparison between two independent studies examining the 5-HT3 receptor in the IC provides evidence for this hypothesis. One of these studies measured responses to current injection in vitro (Miko and Sanes, 2009). Following strong stimulation of lemniscal input fibers, the spiking response to a threshold-level current injection exhibited a short-term change in gain, usually facilitation, lasting seconds to minutes. Blockade of the 5-HT3 receptor removed or reduced the effect of fiber stimulation on gain control, at the same time reducing an associated depolarization of membrane potential. In contrast, antagonists of multiple other transmitter pathways, including ionotropic GABAergic and glycinergic receptors and both nicotinic and muscarinic cholinergic receptors, facilitated the change in gain. Furthermore, a similar decrease in positive gain was created by blockade of L-type calcium channels. These results all suggest an induction of plasticity in response gain by the 5-HT3 receptor, potentially by the postsynaptic admission of calcium (Miko and Sanes, 2009).

In a companion study in vivo, the effect of activating the 5-HT3 receptor corresponded to the level of spiking (Bohorquez and Hurley, 2009). Across the IC neuron population, higher rates of evoked spiking were associated with larger effects of 5 -HT3 receptor activation. In a subset of single neurons, the effect of 5-HT3 receptor activation varied depending on the stimulus repetition rate and consequent spike rate per stimulus (Figure 6). As the stimulus presentation rate increased, associated with a decrease in the spike number, the effect of the 5-HT3 receptor shifted from relative suppression to relative facilitation. Functionally, the 5-HT3 agonist flattened the relationship between stimulus presentation rate and spike rate, in effect equalizing neural responses across different repetition rates. Together, these in vitro and in vivo studies suggest that the 5 -HT3 receptor underlies a form of short-term plasticity in the IC, altering response gain in an activity-dependent manner, and potentially acting to stabilize the level of activity of IC neurons to stimulus trains. 

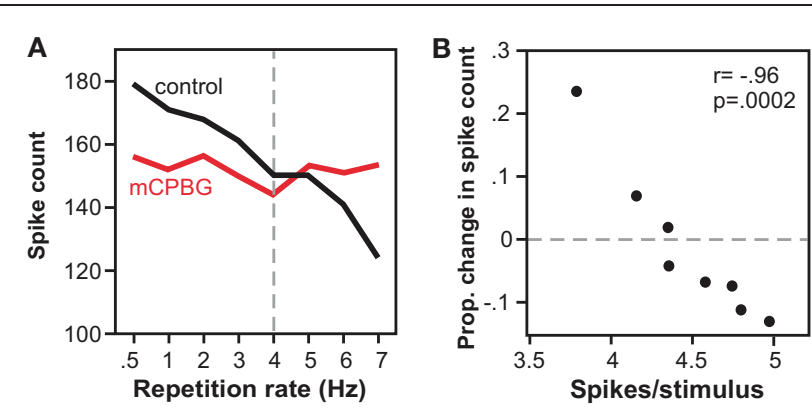

FIGURE 6 | Effects of the 5-HT3 receptor vary with stimulus repetition rate and spike rate. (A) Spike counts decrease with repetition rate in the control, but not during iontophoresis of a 5-HT3 agonist (mCPBG) for a single IC neuron. Stimulus consisted of a $20 \mathrm{~ms}$ tone at $13 \mathrm{kHz}$. (B) The same data as in $(\mathbf{A})$ is plotted as a function of $\mathrm{mCPBG}$-evoked change in spike count versus control spike rate. The 5-HT3 agonist increases spike count at low spike rates, and decreases spike count at high spike rates. All panels were reprinted with permission from Elsevier; additional information on the source article can be found in the Acknowledgments.

\section{INTERACTIONS OF RECEPTORS CREATE NOVEL COMBINATIONS OF EFFECTS}

As instructive as it is to understand the effects of individual serotonin receptor types, a realistic model of the effects of serotonin in the IC must involve some degree of receptor interaction, because multiple receptor types would likely be co-activated by the release of serotonin. With the diversity of receptor types in the IC, many of which have disparate cellular modes of action and distinct effects on evoked activity, predicting the nature of receptor interaction is not a straightforward matter. A study on the interactions of two specific serotonin receptor types within the same receptor family, the 5-HT1A and 5-HT1B receptor, illustrates this point.

The 5-HT1A and 5-HT1B receptors make an interesting comparison, since both are expressed widely among IC neurons (Thompson et al., 1994; Peruzzi and Dut, 2004), and activation of each receptor type correspondingly influences evoked responses of a large proportion of IC neurons. As described earlier, the effects of these receptors on evoked activity in response to tones are opposite, in that activation of the 5-HT1A receptor suppresses evoked responses and in some neurons reduces the bandwidth of frequency tuning, while activation of the 5-HT1B receptor facilitates evoked responses and often increases the bandwidth of frequency tuning. Each receptor also influences the timing of evoked responses for some neurons, with the 5-HT1A receptor usually increasing first-spike latency and ISI, and the 5-HT1B receptor often decreasing first-spike latency and ISI.

If they are not to simply antagonize each other, there are several potential ways for the 5-HT1A and 5-HT1B receptor to functionally interact. One of these is that they are segregated from each other on separate local circuits in the IC, so that they do not directly interact at all. In support of this, some IC neurons show disproportionately greater effects of activation of either the 5-HT1A or 5-HT1B receptors. Functional segregation of the two receptor types is not the complete solution to the puzzle of receptor interaction, however, because many IC neurons show substantial responses to individual activation of both receptor types (Ramsey et al., 2010). This suggests that both receptor types do influence the same local circuitry, as reflected in the activity of a single neuron. For these multiple-responsive neurons 5-HT1A and 5-HT1B receptors do not simply antagonize each other. When activated concurrently, an interesting differential effect of the two receptors types on spike rate versus spike timing emerges. For measures of evoked activity that reflect spike number, including spike rate at the characteristic frequency or the bandwidth of frequency tuning, the receptors do interact additively. That is, the effect of combinatorial activation of the two receptor types on spike rate can generally be predicted by summating the effect of each receptor type alone for a given neuron. In contrast, the 5-HT1A receptor dominates measures of spike timing including the first-spike latency and ISI, so that only the effect of the 5-HT1A receptor predicts the effect of the drug combination. These results fit the model of the 5-HT1A receptor as located postsynaptically on soma and dendrites, exerting control over the timing of spikes by causing potassium channels to open. These findings not only provide a resolution to the puzzle of receptor co-activation, but suggest that general suppression of responsiveness (5-HT1A) combined with presynaptic disinhibition (5-HT1B) can create novel aggregate effects, even for simple sounds such as tones at CF.

\section{CONCLUSIONS}

The experiments described above support the model of different serotonin receptor types as gates to separate but interacting effector pathways. As such, they are a critical node gating the route from behavioral context to the function of the circuitry of the IC. Table 1 and Figure 7 summarize the outcomes of studies on different receptor types in the IC and present a simplified model of the role of these receptors in the excitatory-inhibitory circuitry of the IC. Many features of this model, such as whether particular receptor types play special roles in specific contexts by virtue of their dynamics or closeness to serotonin release sites, are still murky. Nevertheless, the model provides a key for specific predictions in two broad areas of interest in understanding auditory function: (1) the role of the serotonergic system in specific behavioral contexts such as social interaction, and (2) how plasticity in the serotonergic system could alter the relationship between behavioral context and auditory processing or perception.

\section{CONTEXT-DEPENDENCE OF SEROTONERGIC REGULATION}

The measurement of serotonin in the IC of behaving animals suggests that serotonin regulates auditory processing in multiple behavioral contexts, including in waking states, in response to stressful or potentially threatening events, and during social interactions. Changes in serotonin that occur during the latter are worth examining in some detail, since they track behaviorally salient aspects of social interactions such as individual variation in social responses, experience, and age. In mice in which serotonin has been measured in the IC using voltammetry, individual differences in the serotonergic response to a novel social partner are quite pronounced, and correspond to social behaviors such as anogenital investigation and to nonsocial behaviors such as the overall level of activity (Hall et al., 2011). These behavioral correlations suggest that the serotonergic signal in the IC 
Table 1 | Summary of the effects of different serotonin receptor types in the IC.

\begin{tabular}{|c|c|c|c|}
\hline 5-HT receptor type & Localization & Preparation & Effects in IC \\
\hline $1 \mathrm{~B}$ & axonal/terminal ${ }^{2}$ & in vivo ${ }^{\mathrm{a}, \mathrm{c}}$ & increases evoked responses \\
\hline $2 \mathrm{C}$ & postsynaptic density, somatodendritic ${ }^{4}$ & in vivo ${ }^{a}$ & increases evoked responses \\
\hline $2 \mathrm{~A} / \mathrm{C}$ & - & in vivo ${ }^{a}$ & decreases evoked responses \\
\hline
\end{tabular}

${ }^{1}$ Hannon and Hoyer, 2008; ${ }^{2}$ Sari, 2004; ${ }^{3}$ Bombardi, 2012; Jakab and Goldman-Rakic, 1998; ${ }^{4}$ Anastasio et al., $2010 ;$ Liu et al., $2007 ;{ }^{5}$ Carrillo et al., 2010; a Hurley, 2006; ${ }^{b}$ Hurley, 2007; ' ${ }^{c}$ Hurley et al., 2008; ' Wang et al., 2008; e Miko and Sanes, 2009; Bohorquez and Hurley, 2009.

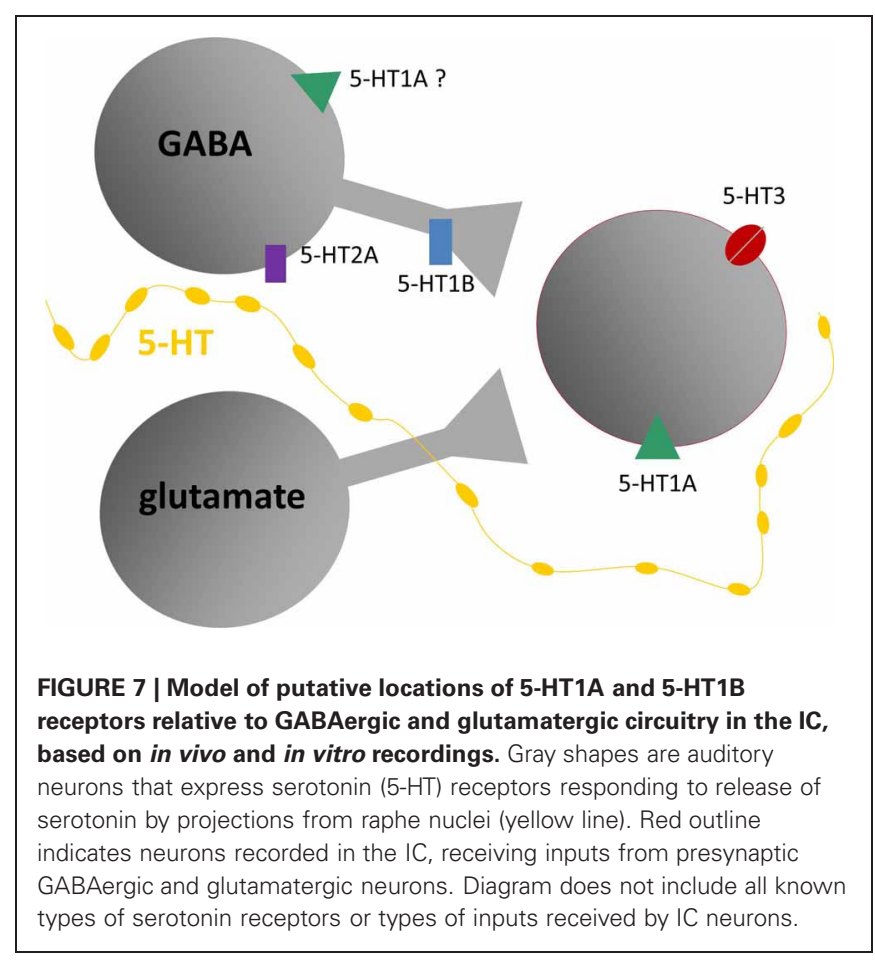

conveys information about the responsiveness of individual mice to a social stimulus. Moreover, being in a social experiment leaves a long-lasting trace, since both the serotonergic signal in the IC and some behaviors are increased in male mice undergoing a second social encounter occurring one week later, although this could be an effect of either the social interaction itself or of stress (Figure 8). Finally, predictable factors like age also significantly correlate with not only the serotonergic response to a social encounter but also the density of serotonergic fibers, both of which decrease over a period of young adulthood (Hall et al., 2011). All of these results describe a regulatory signal that varies with socially salient information.

The IC and its homologs, including the torus semicircularis in amphibians and fish and the mesencephalicus lateralis, pars dorsalis (MLd) in birds, are important early processing centers for auditory signals produced in social interactions. Behaviorally, the auditory midbrain is necessary for responses to mate calls in some species (Endepols et al., 2003). Stimulus-evoked gene activity in the torus semicircularis reflects discrimination among different vocal signals, sometimes in a sex-specific manner (Hoke et al., 2004, 2010; Mangiamele and Burmeister, 2011). Furthermore, the processing of social vocalizations in auditory midbrain nuclei is context-dependent, in that neural responses vary with natural or experimental manipulation of reproductive state, or with salient factors such as the prospect of reward (Goense and Feng, 2005; Maney et al., 2006; Metzger et al., 2006; Miranda and Wilczynski, 2009a,b).

Consistent with these more global measures of the discrimination of social signals, individual IC neurons may themselves be selective for communication calls. With some exceptions, auditory midbrain neurons in a wide range of species show greater responses for auditory signals over nonvocalization sounds with similar characteristics (including time-reversed vocalizations), and may further be selective for specific vocalizations (Diekamp and Schneider, 1988; Bodnar and Bass, 1997; Crawford, 1997; Alder and Rose, 2000; Woolley et al., 2006; Andoni et al., 2007; Pincherli Castellanos et al., 2007; Suta et al., 2007, 2008; Andoni and Pollak, 2011; Elliott et al., 2011). In demonstrating selectivity for vocalizations, auditory midbrain neurons differ from neurons in some lower auditory nuclei. IC neurons show a higher level of vocalization selectivity than neurons that project to the IC from the dorsal and intermediate nuclei of the lateral lemniscus as a result of the convergence of inhibitory and excitatory inputs (Klug et al., 2002; Xie et al., 2005). Additional spectral or temporal coding mechanisms further contribute to selective midbrain responses (Epping, 1990; Bodnar and Bass, 1997; Leroy and Wenstrup, 2000; Bauer et al., 2002; Klug et al., 2002; Yavuzoglu et al., 2010; Andoni and Pollak, 2011; Pollak et al., 2011; Schneider and Woolley, 2011; Yavuzoglu et al., 2011), and patterns at the level of the neuron population may further increase the selectivity of vocalization encoding (Bodnar et al., 2001; Holmstrom et al., 2010; Schneider and Woolley, 2010).

Completing the link between serotonin and social situations, serotonin directly modifies the processing of social stimuli in the IC. In in vivo experiments in Mexican free-tailed bats, exogenously applied serotonin modulates the responses of individual IC neurons to playback of vocalizations from social interactions (Hurley and Pollak, 2005a). For most neurons, serotonin increases the selectivity of neural responses across a range of calls. Based on the regulation of less complex stimuli by different receptor types, reasonable predictions are that the modulation of vocalization responses by particular receptor types 


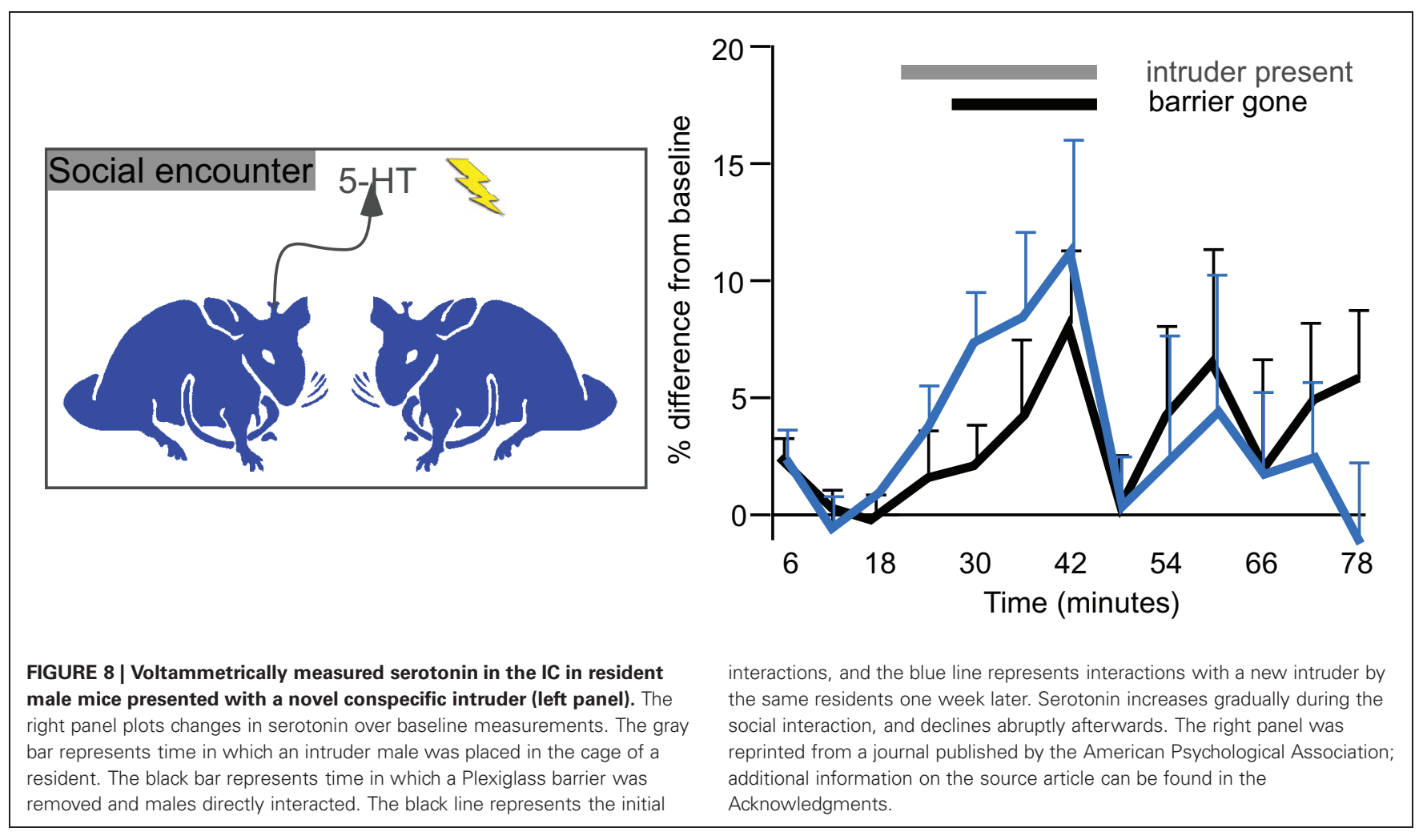

should vary among neurons, should depend in part on the structure of a given call, and that different serotonin receptor types may interact to influence vocalization coding in novel ways.

All of this information on serotonergic function in the IC at multiple levels of analysis suggests a possible scenario of the role of serotonin in social encounters. During social interactions, serotonin in the IC would steadily increase over the course of a social interaction, and would be related to the magnitude of the behavioral response. Many IC neurons would show a parallel increase in selectivity for vocalizations or other sounds produced during the encounter. Overall, this could create population-level responses for different vocalizations that are more distinct from each other in the presence of serotonin. This scenario serves as the basis for an as yet untested prediction that behavioral responses to social vocalizations correspond to levels of serotonin in the IC.

\section{SEROTONIN-AUDITORY PLASTICITY; A CHANNEL FOR PAST EXPERIENCE}

An exciting prospect that has emerged as a result of work in the IC and other sensory regions is that plasticity in the infrastructure of the serotonergic system itself can provide a route for information about past events to influence neural circuitry. Plasticity in serotonergic-IC interactions occurs under a number of different conditions. The experience of acoustic trauma alters a fundamental aspect of the serotonergic system, the density of fibers within the IC. This is seen when a unilateral tonal trauma creates an imbalance in the density of serotonergic fibers between contralateral colliculi, with the IC contralateral to the traumatized ear having a lower density of fibers than the IC contralateral to the protected ear (Figure 9; Papesh and Hurley, 2012). Plasticity in the serotonergic system may also be guided by internal factors including age and reproductive state. Age influences both the density of serotonergic fibers and acute changes in serotonin, such that both fiber density and serotonin release during social encounters decline over young adulthood in mice (Hall et al., 2011; Papesh and Hurley, 2012). In older animals, serotonin content may rise again in the IC or other auditory regions (Cransac et al., 1996; Shim et al., 2012). Reproductive readiness, via gonadal hormones, also increases serotonergic fiber density in the avian auditory midbrain (Matragrano et al., 2012).

Plasticity is also observed at the level of serotonin receptors. With increasing age from adulthood through old age, the 5-HT2B receptor is upregulated in the IC (Tadros et al., 2007). Expression of this receptor type is further upregulated in old mice with severe hearing loss. The amount of expression of the 5-HT2B receptor is correlated with functional metrics of hearing such as the amplitude of the distortion product otoacoustic emission (DPOAE) and with the threshold of the ABR. In addition to age, peripheral damage leads to receptor plasticity. Following cochlear ablation, the expression of both 5-HT2C and 5-HT5B receptors is altered, but in different directions and with different dynamics. 5-HT2C expression increases from 3 through 90 days following ablation, and 5-HT5B receptor expression decreases from 5-21 days, and recovers by 90 days following ablation (Holt et al., 2005). Thus, the balance of different serotonin receptor types may be altered by plastic responses to aging or peripheral 


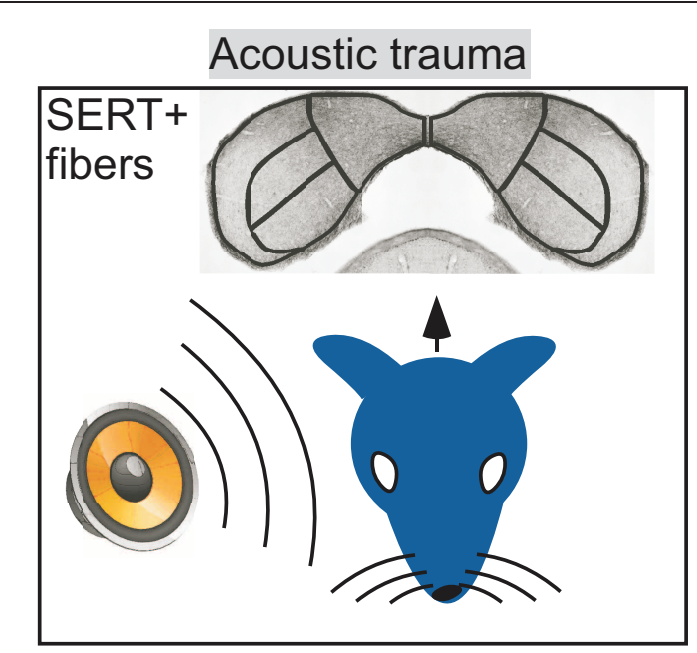

FIGURE 9 | Comparison of the density of serotonergic fibers in the IC contralateral versus ipsilateral to an ear exposed to $8 \mathrm{kHz}$ acoustic trauma. Left panel depicts the monaural trauma and subsequent immunolabeling of SERT-positive projections in the IC. Right panel shows percentage differences in fiber density in the IC contralateral to acoustic

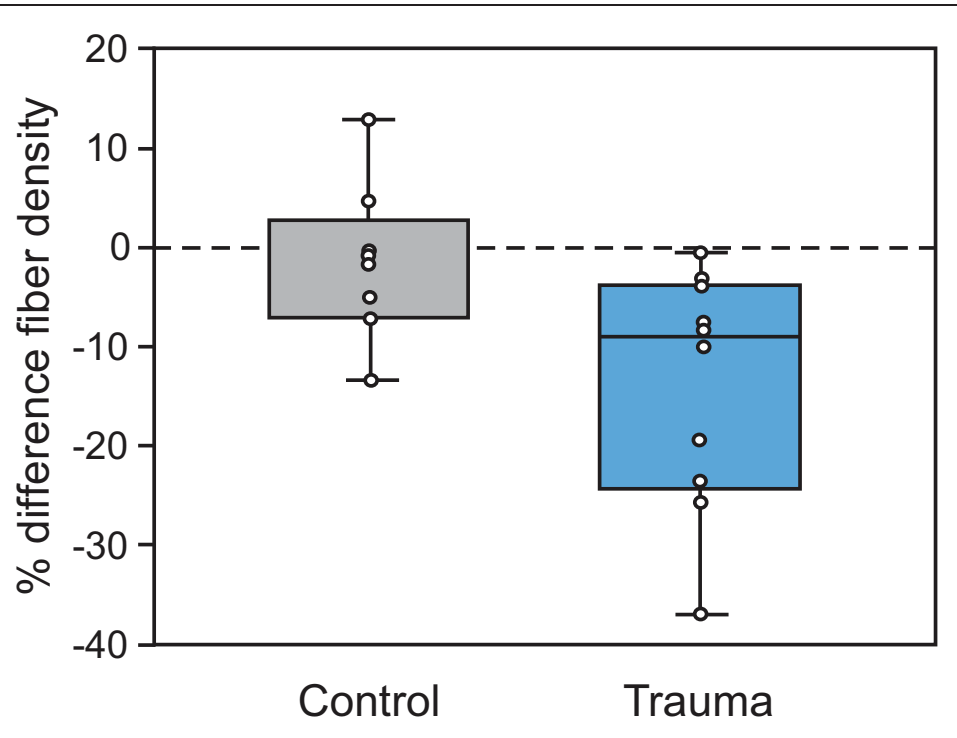

trauma relative to the $\mathrm{IC}$ ipsilateral to the trauma, in $10 \mathrm{CBA} / \mathrm{J}$ mice. Fiber density is lower in the contralateral relative to the ipsilateral IC in the trauma group, but not for the control group that did not receive trauma. The right panel was reprinted with permission from Elsevier; additional information on the source article can be found in the Acknowledgments. damage. Whether this creates qualitative changes in the modulatory effects of serotonin on auditory processing in the IC is unknown.

Predicting the functional importance of changes in the serotonergic infrastructure following events such as acoustic trauma is even more complex against the background of changes in other neurochemical signaling systems. Multiple events that create plasticity in the serotonergic system, such as acoustic trauma, are well-known for triggering plasticity in both excitatory and inhibitory neurotransmitter systems in the IC (Milbrandt et al., 2000; Dong et al., 2010; Browne et al., 2012). Such changes may result in shifts in excitatory-inhibitory balance in association with pathologies such as tinnitus and hyperacusis (Szczepaniak and Moller, 1996; Eggermont and Roberts, 2004). For example, experiments in the IC have demonstrated neurochemical and functional changes related to inhibition after acoustic trauma that have been associated with hyperexcitability of IC neurons (Salvi et al., 1990; Milbrandt et al., 2000; Salvi et al., 2000; Alvarado et al., 2005; Izquierdo et al., 2008; Browne et al., 2012). Given the evidence for serotonergic regulation of both inhibitory and excitatory neural responses in the IC, understanding exactly how events like acoustic trauma alter the regulation of excitability through particular receptor types is a topic that will require additional exploration.

Although plasticity at multiple levels is turning out to be a prominent feature of serotonergic-auditory interactions, whether particular types of changes represent developmental programs, homeostatic responses to peripheral damage, or pathological consequences of damage has not been addressed. Some insight into these issues may be gained from recent studies on the role of serotonin in visual plasticity. In rat visual cortex, ocular dominance plasticity, normally highly limited in adults relative to juveniles, is augmented by systemic administration of fluoxetine, a selective serotonin reuptake inhibitor (Maya Vetencourt et al., 2008). Other treatments that increase serotonin levels in the visual cortex, even behavioral treatments such as environmental enrichment, also augment ocular dominance plasticity (Baroncelli et al., 2010).

In light of this work, plasticity in the serotonergic system within the IC has several important implications for auditory function. One of these is based on the role of serotonin in mediating the influence of behavioral context. Plasticity in the serotonergic system could alter the relationship between behavioral context and auditory processing, leading to either more adaptive or pathological modulation of auditory responses during social interactions or stressful situations. If serotonin gates experiencedependent plasticity in the IC as it does in visual cortex, an alteration in the serotonergic system could additionally recast the ability of the auditory system to express adaptive plasticity. Both of these are exciting possibilities for future experimental attention.

\section{GENERAL CONCLUSIONS}

An increasing number of studies on the influence of serotonin in the IC have been completed in the last decade. Despite this, an understanding of serotonergic regulation in the IC, and indeed of the neuromodulation of auditory processing in general, is in its infancy. Here we have made the case that serotonin provides a channel for contextual information about internal state, external events, and even past experience. This information is then transformed into specific changes in the function of the neural circuits of the IC through parallel but interacting receptor pathways. Plasticity in the infrastructure of the serotonergic system, including within specific receptor pathways, could potentially alter the 
relationship between behavioral context and circuit function in important ways that have yet to be explored.

\section{ACKNOWLEDGMENTS}

This work was supported in part by a grant from the National Institute on Deafness and Other Communication Disorders (DC-008963). Figure 3 was reprinted from the J. Neurophysiol. Vol. 96, 2177-2188, Hurley, Copyright (2006), with permission from the American Physiological Society. Part of Figure 4 was reprinted from the J. Neurophysiol. Vol. 100, 1656-1667, Hurley et al., Copyright (2008), with permission from the American Physiological Society. Figure 5 was reprinted from Brain Res. Vol. 1181, 21-29, Hurley, Copyright (2007), with permission from Elsevier. Figure 6 was reprinted from Hear. Res. Vol. 251, 29-38, Bohorquez and Hurley, Copyright (2009), with permission from Elsevier. Part of Figure 8 was reprinted from Behav. Neurosci. Vol. 125, 501-511, Hall et al., Copyright (2011), with permission from the American Psychological Association. Part of Figures $\mathbf{1}$ and $\mathbf{8}$ were reprinted from Hear. Res. Vol. 283, 89-97, Papesh and Hurley, Copyright (2012), with permission from Elsevier.

\section{REFERENCES}

Adams, J. C., and Mugnaini, E. (1984). Dorsal nucleus of the lateral lemniscus: a nucleus of GABAergic projection neurons. Brain Res. Bull. 13, 585-590.

Alder, T. B., and Rose, G. J. (2000). Integration and recovery processes contribute to the temporal selectivity of neurons in the midbrain of the northern leopard frog, Rana pipiens. J. Comp. Physiol. A 186, 923-937.

Alvarado, J. C., Fuentes-Santamaria, V., Franklin, S. R., Brunso-Bechtold, J. K., and Henkel, C. K. (2005). Unilateral cochlear ablation in adult ferrets results in upregulation in calretinin immunostaining in the central nucleus of the inferior colliculus. Neuroscience 136, 957-969.

Anastasio, N. C., Lanfranco, M. F., Bubar, M. J., Seitz, P. K., Stutz, S. J., McGinnis, A. G., Watson, C. S., and Cunningham, K. A. (2010). Serotonin 5-HT2C receptor protein expression is enriched in synaptosomal and post-synaptic compartments of rat cortex. J. Neurochem. 113, 1504-1515.

Andoni, S., Li, N., and Pollak, G. D. (2007). Spectrotemporal receptive fields in the inferior colliculus revealing selectivity for spectral motion in conspecific vocalizations. J. Neurosci. 27, 4882-4893.

Andoni, S., and Pollak, G. D. (2011). Selectivity for spectral motion as a neural computation for encoding natural communication signals in bat inferior colliculus. J. Neurosci. 31, 16529-16540.

Baroncelli, L., Sale, A., Viegi, A., Maya Vetencourt, J. F., De Pasquale, R., Baldini, S., and Maffei, L. (2010). Experience-dependent reactivation of ocular dominance plasticity in the adult visual cortex. Exp. Neurol. 226, 100-109.

Bauer, E. E., Klug, A., and Pollak, G. D. (2002). Spectral determination of responses to species-specific calls in the dorsal nucleus of the lateral lemniscus. J. Neurophysiol. 88, 1955-1967.

Bodnar, D. A., and Bass, A. H. (1997). Temporal coding of concurrent acoustic signals in auditory midbrain. J. Neurosci. 17 7553-7564.

Bodnar, D. A., Holub, A. D., Land, B. R., Skovira, J., and Bass, A. H. (2001). Temporal population code of concurrent vocal signals in the auditory midbrain. J. Comp. Physiol. A. Neuroethol. Sens. Neural. Behav. Physiol. 187, 865-873.

Bohorquez, A., and Hurley, L. M. (2009). Activation of serotonin 3 receptors changes in vivo auditory responses in the mouse inferior colliculus. Hear. Res. 251, 29-38.

Bombardi, C. (2012). Neuronal localization of 5-HT2A receptor immunoreactivity in the rat hippocampal region. Brain Res. Bull. 87, 259-273.

Boutelle, M. G., Zetterstrom, T., Pei, Q., Svensson, L., and Fillenz, M. (1990). In vivo neurochemical effects of tail pinch. J. Neurosci. Methods 34, 151-157.

Bowery, N. (1989). GABAB receptors and their significance in mammalian pharmacology. Trends Pharmacol. Sci. 10, 401-407.

Browne, C. J., Morley, J. W., and Parsons, C. H. (2012). Tracking the expression of excitatory and inhibitory neurotransmissionrelated proteins and neuroplasticity markers after noise induced hearing loss. PLOS ONE 7:e33272. doi: 10.1371/journal.pone.0033272

Bunin, M. A., and Wightman, R. M. (1999). Paracrine neurotransmission in the CNS: involvement of 5-HT. Trends Neurosci. 22, 377-382.

Burger, R. M., and Pollak, G. D. (2001). Reversible inactivation of the dorsal nucleus of the lateral lemniscus reveals its role in the processing of multiple sound sources in the inferior colliculus of bats. J. Neurosci. 21, 4830-4843.
Carrillo, M., Ricci, L. A., Schwartzer, J. J., and Melloni, R. H. (2010). Immunohistochemical characterization of 5-HT(3A) receptors in the Syrian hamster forebrain. Brain Res. 1329, 67-81.

Casseday, J. H., Ehrlich, D., and Covey, E. (1994). Neural tuning for sound duration- role of inhibitory mechanisms in the inferior colliculus Science 264, 847-850.

Casseday, J. H., Ehrlich, D., and Covey, E. (2000). Neural measurement of sound duration: control by excitatory-inhibitory interactions in the inferior colliculus. J. Neurophysiol. 84, 1475-1487.

Celio, M. R. (1990). Calbindin-d-28k and parvalbumin in the rat nervoussystem. Neuroscience 35, 375-475.

Chalmers, D. T., and Watson, S. J. (1991). Comparative anatomical distribution of 5-HT1A receptor mRNA and 5-HT1A binding in rat brain-a combined in situ hybridisation/in vitro receptor autoradiographic study. Brain Res. 561, 51-60.

Chameau, P., and Van Hooft, J. A (2006). Serotonin 5-HT(3) receptors in the central nervous system. Cell Tissue Res. 326, 573-581.

Charitidi, K., and Canlon, B. (2010). Estrogen receptors in the central auditory system of male and female mice. Neuroscience 165 , 923-933.

Ciranna, L. (2006). Serotonin as a modulator of glutamate- and GABA-mediated neurotransmission: implications in physiological functions and in pathology. Curr. Neuropharmacol. 4, 101-114.

Clement, H. W., Kirsch, M., Hasse, C., Opper, C., Gemsa, D., and Wesemann, W. (1998). Effect of repeated immobilization on serotonin metabolism in different rat brain areas and on serum corticosterone. J. Neural Transm. 105, 1155-1170.

Cransac, H., Peyrin, L., Cottet-Emard, J. M., Farhat, F., Pequignot, J. M., and Reber, A. (1996). Aging effects on monoamines in rat medial vestibular and cochlear nuclei. Hear. Res. 100, 150-156.

Crawford, J. D. (1997). Featuredetecting auditory neurons in the brain of a sound-producing fish. J. Comp. Physiol. A 180, 439-450.

Cuccurazzu, B., and Halberstadt, A. L. (2008). Projections from the vestibular nuclei and nucleus prepositus hypoglossi to dorsal raphe nucleus in rats. Neurosci. Lett. 439, 70-74.

Defelipe, J., Hendry, S. H., Hashikawa, T., and Jones, E. G. (1991) Synaptic relationships of serotoninimmunoreactive terminal baskets on GABA neurons in the cat auditory cortex. Cereb. Cortex 1, 117-133.

Dehmel, S., Cui, Y. L., and Shore, S. E. (2008). Cross-modal interactions of auditory and somatic inputs in the brainstem and midbrain and their imbalance in tinnitus and deafness. Am. J. Audiol. 17 S193-S209.

Diekamp, B., and Schneider, H. (1988). Neuronal processing of conspecific and related calls in the torus semicircularis of Rana $r$. ridibunda Pall. (Anura): single-unit recordings. J. Comp. Physiol. A 163, 301-315.

Dong, S., Mulders, W. H., Rodger, J., Woo, S., and Robertson, D (2010). Acoustic trauma evokes hyperactivity and changes in gene expression in guinea-pig auditory brainstem. Eur. J. Neurosci. 31, 1616-1628.

Duncan, G. E., Knapp, D. J., Breese, G. R., Crews, F. T., and Little, K. Y. (1998). Species differences in regional patterns of $\mathrm{H}-3-8$ OH-DPAT and H-3-zolpidem binding in the rat and human brain. Pharmacol. Biochem. Behav. 60, 439-448.

Eggermont, J. J., and Roberts, L. E. (2004). The neuroscience of tinnitus. Trends Neurosci. 27, 676-682. 
Elliott, T. M., Christensen-Dalsgaard, J., and Kelley, D. B. (2011). Temporally selective processing of communication signals by auditory midbrain neurons. J. Neurophysiol. 105, 1620-1632.

Endepols, H., Feng, A. S., Gerhardt, H. C., Schul, J., and Walkowiak, W. (2003). Roles of the auditory midbrain and thalamus in selective phonotaxis in female gray treefrogs (Hyla versicolor). Behav. Brain Res. 145, 63-77.

Engelhardt, J. K., Silveira, V., Morales, F. R., Pose, I., and Chase, M. H. (2010). Serotoninergic control of glycinergic inhibitory postsynaptic currents in rat hypoglossal motoneurons. Brain Res. 1345, 1-8.

Epping, W. J. (1990). Influence of adaptation on neural sensitivity to temporal characteristics of sound in the dorsal medullary nucleus and torus semicircularis of the grassfrog. Hear. Res. 45, 1-13.

Faingold, C. L., Anderson, C. A., and Randall, M. E. (1993). Stimulation or blockade of the dorsal nucleus of the lateral lemniscus alters binaural and tonic inhibition in contralateral inferior colliculus neurons. Hear. Res. 69, 98-106.

Farley, G. R., Morley, B. J., Javel, E., and Gorga, M. P. (1983). Single-unit responses to cholinergic agents in the rat inferior colliculus. Hear. Res. 11, 73-91.

Fitzgerald, K. K., and Sanes, D. H. (1999). Serotonergic modulation of synapses in the developing gerbil lateral superior olive. $J$. Neurophysiol. 81, 2743-2752.

Freund, T. F., Gulyas, A. I., Acsady, L., Gorcs, T., and Toth, K. (1990). Serotonergic control of the hippocampus via local inhibitory interneurons. PNAS 87, 8501-8505.

Fubara, B. M., Casseday, J. H., Covey, E., and Schwartzbloom, R. D. (1996). Distribution of GABA(A) $\operatorname{GABA}(\mathrm{B})$, and glycine receptors in the central auditory system of the big brown bat, Eptesicus fuscus. J. Comp. Neurol. 369, 83-92.

Funai, H., and Funasaka, S. (1983). Experimental study on the effect of inferior colliculus lesions upon auditory brain stem response. Audiology 22, 9-19.

Fuzessery, Z. M., and Hall, J. C. (1996). Role of GABA in shaping frequency tuning and creating FM sweep selectivity in the inferior colliculus. J. Neurophysiol. 76, 1059-1073.

Gasser, P. J., Orchinik, M., Raju, I., and Lowry, C. A. (2009). Distribution of organic cation transporter 3, a corticosteronesensitive monoamine transporter, in the rat brain. J. Comp. Neurol. 512, 529-555.

Goense, J. B., and Feng, A. S. (2005). Seasonal changes in frequency tuning and temporal processing in single neurons in the frog auditory midbrain. J. Neurobiol. 65, 22-36.

Gonzalez-Hernandez, T., MantolanSarmiento, B., Gonzalez-Gonzalez, B., and Perez-Gonzalez, H. (1996). Sources of GABAergic input to the inferior colliculus of the rat. J. Comp. Neurol. 372, 309-326.

Greco, B., Edwards, D. A., Michael, R. P., Zumpe, D., and Clancy, A. N. (1999). Colocalization of androgen receptors and mating-induced FOS immunoreactivity in neurons that project to the central tegmental field in male rats. J. Comp. Neurol. 408 220-236.

Groh, J. M., Trause, A. S., Underhill, A. M., Clark, K. R., and Inati, S. (2001). Eye position influences auditory responses in primate inferior colliculus. Neuron 29, 509-518.

Habbicht, H., and Vater, M. (1996). A microiontophoretic study of acetylcholine effects in the inferior colliculus of horseshoe bats: implications for a modulatory role. Brain Res. 724, 169-179.

Hall, I. C., and Hurley, L. M. (2007). The serotonin releaser fenfluramine alters the auditory responses of inferior colliculus neurons. Hear. Res 228, 82-94.

Hall, I. C., Rebec, G. V., and Hurley, L. M. (2010). Serotonin in the inferior colliculus fluctuates with behavioral state and environmental stimuli. J. Exp. Biol. 213, 1009-1017.

Hall, I. C., Sell, G. L., and Hurley, L. M. (2011). Social regulation of serotonin in the auditory midbrain Behav. Neurosci. 125, 501-511.

Hannon, J., and Hoyer, D. (2008). Molecular biology of 5-HT receptors. Behav. Brain Res. 195, 198-213.

Harris-Warrick, R. M. (2011). Neuromodulation and flexibility in central pattern generator networks. Curr. Opin. Neurobiol. 21, 685-692.

Hernandez, O., Rees, A., and Malmierca, M. S. (2006). A GABAergic component in the commissure of the inferior colliculus in rat. Neuroreport 17, 1611-1614.

Heym, J., Trulson, M. E., and Jacobs, B. L. (1982). Raphe unit activity in freely moving cats: effects of phasic auditory and visual stimuli. Brain Res. 232, 29-39.

Hoffman, B. J., Hansson, S. R., Mezey, E., and Palkovits, M. (1998). Localization and dynamic regulation of biogenic amine transporters in the mammalian central nervous system. Front. Neuroendocrinol. 19, 187-231.

Hoke, K. L., Burmeister, S. S., Fernald, R. D., Rand, A. S., Ryan, M. J., and Wilczynski, W. (2004). Functional mapping of the auditory midbrain during mate call reception. $J$. Neurosci. 24, 11264-11272.

Hoke, K. L., Ryan, M. J., and Wilczynski, W. (2010). Sexually dimorphic sensory gating drives behavioral differences in tungara frogs. J. Exp. Biol. 213, 3463-3472.

Holmstrom, L. A., Eeuwes, L. B. Roberts, P. D., and Portfors, C. V. (2010). Efficient encoding of vocalizations in the auditory midbrain J. Neurosci. 30, 802-819.

Holt, A. G., Asako, M., Lomax, C. A., Macdonald, J. W., Tong, L., Lomax, M. I., and Altschuler, R. A. (2005). Deafness-related plasticity in the inferior colliculus: gene expression profiling following removal of peripheral activity. $J$. Neurochem. 93, 1069-1086.

Huffman, R. F., and Henson, O. W. Jr. (1990). The descending auditory pathway and acousticomotor systems: connections with the inferior colliculus. Brain Res. Brain Res. Rev. 15, 295-323.

Hurley, L. M. (2006). Different serotonin receptor agonists have distinct effects on sound-evoked responses in inferior colliculus. J. Neurophysiol. 96, 2177-2188.

Hurley, L. M. (2007). Activation of the serotonin $1 \mathrm{~A}$ receptor alters the temporal characteristics of auditory responses in the inferior colliculus. Brain Res. 1181, 21-29.

Hurley, L. M., Devilbiss, D. M. and Waterhouse, B. D. (2004). A matter of focus: monoaminergic modulation of stimulus coding in mammalian sensory networks. Curr. Opin. Neurobiol. 14, 488-495.

Hurley, L. M., and Hall, I. C. (2011) Context-dependent modulation of auditory processing by serotonin. Hear. Res. 279, 74-84.

Hurley, L. M., and Pollak, G. D. (1999). Serotonin differentially modulates responses to tones and frequency-modulated sweeps in the inferior colliculus. J. Neurosci. 19 8071-8082.

Hurley, L. M., and Pollak, G. D. (2001) Serotonin effects on frequency tuning of inferior colliculus neurons. J. Neurophysiol. 85, 828-842.

Hurley, L. M., and Pollak, G. D (2005a). Serotonin modulates responses to species-specific vocalizations in the inferior colliculus. J. Comp. Physiol. A Neuroethol. Sens. Neural. Behav. Physiol. 191, 535-546.
Hurley, L. M., and Pollak, G. D. (2005b). Serotonin shifts first-spike latencies of inferior colliculus neurons. J. Neurosci. 25, 7876-7886

Hurley, L. M., and Thompson, A. M. (2001). Serotonergic innervation of the auditory brainstem of the Mexican free-tailed bat, Tadarida brasiliensis. J. Comp. Neurol. 435, 78-88.

Hurley, L. M., Thompson, A. M., and Pollak, G. D. (2002). Serotonin in the inferior colliculus. Hear. Res $168,1-11$.

Hurley, L. M., Tracy, J. A., and Bohorquez, A. (2008). Serotonin $1 \mathrm{~B}$ receptor modulates frequency response curves and spectral integration in the inferior colliculus by reducing GABAergic inhibition. J. Neurophysiol. 100, 1656-1667.

Ito, T., Bishop, D. C., and Oliver, D. L. (2009). Two classes of GABAergic neurons in the inferior colliculus. J. Neurosci. 29, 13860-13869.

Izquierdo, M. A., Gutierrez-Conde, P. M., Merchan, M. A., and Malmierca, M. S. (2008). Nonplastic reorganization of frequency coding in the inferior colliculus of the rat following noise-induced hearing loss. Neuroscience 154, 355-369.

Jacobs, B. L., and Fornal, C. A. (1999). Activity of serotonergic neurons in behaving animals. Neuropsychopharmacology 21, 9S-15S.

Jakab, R. L., and Goldman-Rakic, P. S. (1998). 5-Hydroxytryptamine2A serotonin receptors in the primate cerebral cortex: possible site of action of hallucinogenic and antipsychotic drugs in pyramidal cell apical dendrites. Proc. Natl. Acad. Sci. U.S.A. 95, 735-740.

Jakab, R. L., and Goldman-Rakic, P. S. (2000). Segregation of serotonin 5-HT2A and 5-HT3 receptors in inhibitory circuits of the primate cerebral cortex. J. Comp. Neurol. 417, 337-348.

Ji, W., and Suga, N. (2009). Tonespecific and nonspecific plasticity of inferior colliculus elicited by pseudo-conditioning: role of acetylcholine and auditory and somatosensory cortices. $J$. Neurophysiol. 102, 941-952.

Kaga, K., Yamada, K., Tsuzuku, T., and Uno, A. (1999). The long-term effect of bilateral inferior colliculus ablation on auditory brainstem response in awake cats. Acta Otolaryngol. 119, 128-131. 
Kaiser, A., and Covey, E. (1997). "5-HT innervation of the auditory pathway in birds and bats," in Acoustical Signal Processing in the Central Auditory System, ed J. L. Syka (New York, NY: Plenum), 71-78.

Kawano, H., Decker, K., and Reuss, S. (1996). Is there a direct retinaraphe-suprachiasmatic nucleus pathway in the rat? Neurosci. Lett. $212,143-146$.

Kidd, S. A., and Kelly, J. B. (1996). Contribution of the dorsal nucleus of the lateral lemniscus to binaural responses in the inferior colliculus of the rat: interaural time delays. J. Neurosci. 16, 7390-7397.

Kishimoto, K., Koyama, S., and Akaike, N. (2001). Synergistic mu-opioid and 5-HT1A presynaptic inhibition of GABA release in rat periaqueductal gray neurons. Neuropharmacology 41, 529-538.

Klepper, A., and Herbert, H. (1991). Distribution and origin of noradrenergic and serotonergic fibers in the cochlear nucleus and inferior colliculus of the rat. Brain Res. 557, 190-201.

Klug, A., Bauer, E. E., Hanson, J. T., Hurley, L., Meitzen, J., and Pollak, G. D. (2002). Response selectivity for species-specific calls in the inferior colliculus of Mexican freetailed bats is generated by inhibition. J. Neurophysiol. 88, 1941-1954.

Lebeau, F. E., Malmierca, M. S., and Rees, A. (2001). Iontophoresis in vivo demonstrates a key role for $\mathrm{GABA}(\mathrm{A})$ and glycinergic inhibition in shaping frequency response areas in the inferior colliculus of guinea pig. J. Neurosci. 21, 7303-7312.

Lebeau, F. E. N., Rees, A., and Malmierca, M. S. (1996). Contribution of GABA- and glycine-mediated inhibition to the monaural temporal response properties of neurons in the inferior colliculus. J. Neurophysiol. 75 , 902-919.

Lee, H. S., Kim, M. A., Valentino, R. J., and Waterhouse, B. D. (2003). Glutamatergic afferent projections to the dorsal raphe nucleus of the rat. Brain Res. 963, 57-71.

Lee, J. J., Hahm, E. T., Lee, C. H., and Cho, Y. W. (2008). Serotonergic modulation of GABAergic and glutamatergic synaptic transmission in mechanically isolated rat medial preoptic area neurons. Neuropsychopharmacology 33, 340-352.

Leroy, S. A., and Wenstrup, J. J. (2000). Spectral integration in the inferior colliculus of the mustached bat. J. Neurosci. 20, 8533-8541.
Levitt, P., and Moore, R. Y. (1979). Origin and organization of brainstem catecholamine innervation in the rat. J. Comp. Neurol. 186, 505-528.

Liu, S., Bubar, M. J., Lanfranco, M. F., Hillman, G. R., and Cunningham, K. A. (2007). Serotonin2C receptor localization in GABA neurons of the rat medial prefrontal cortex: implications for understanding the neurobiology of addiction. Neuroscience $146,1677-1688$

Lohmann, C., and Friauf, E. (1996), Distribution of the calcium-binding proteins parvalbumin and calretinin in the auditory brainstem of adult and developing rats. J. Comp. Neurol. 367, 90-109.

Lu, Y., and Jen, P. H. (2001). GABAergic and glycinergic neural inhibition in excitatory frequency tuning of bat inferior collicular neurons. Exp. Brain Res. 141, 331-339.

Macdonald, R. L., and Olsen, R. W. (1994). GABA(A) receptor channels. Ann. Rev. Neurosci. 17, 569-602.

Malmierca, M. S., Hernandez, O, Antunes, F. M., and Rees, A. (2009). Divergent and point-to-point connections in the commissural pathway between the inferior colliculi. J. Comp. Neurol. 514, 226-239.

Malmierca, M. S., Hernandez, O. and Rees, A. (2005a). Intercollicular commissural projections modulate neuronal responses in the inferior colliculus. Eur. J. Neurosci. 21, 2701-2710.

Malmierca, M. S., Saint Marie, R. L. Merchan, M. A., and Oliver, D. L. (2005b). Laminar inputs from dorsal cochlear nucleus and ventral cochlear nucleus to the central nucleus of the inferior colliculus: two patterns of convergence. Neuroscience 136, 883-894.

Maney, D. L., Cho, E., and Goode, C. T. (2006). Estrogen-dependent selectivity of genomic responses to birdsong. Eur. J. Neurosci. 23, 1523-1529.

Maney, D. L., and Pinaud, R. (2011). Estradiol-dependent modulation of auditory processing and selectivity in songbirds. Front. Neuroendocrinol. 32, 287-302.

Mangiamele, L. A., and Burmeister, S. S. (2011). Auditory selectivity for acoustic features that confer species recognition in the tungara frog. $J$. Exp. Biol. 214, 2911-2918.

Marsh, R. A., Fuzessery, Z. M., Grose, C. D., and Wenstrup, J. J. (2002). Projection to the inferior colliculus from the basal nucleus of the amygdala. J. Neurosci. 22, 10449-10460.
Mas, M., Fumero, B., and GonzalezMora, J. L. (1995). Voltammetric and microdialysis monitoring of brain monoamine neurotransmitter release during sociosexual interactions. Behav. Brain Res. 71, 69-79.

Matragrano, L. L., Sanford, S. E., Salvante, K. G., Beaulieu, M. Sockman, K. W., and Maney, D. L. (2012). Estradiol-dependent modulation of serotonergic markers in auditory areas of a seasonally breeding songbird. Behav. Neurosci. 126, 110-122.

Maya Vetencourt, J. F., Sale, A., Viegi, A., Baroncelli, L., De Pasquale, R. O'leary, O. F., Castren, E., and Maffei, L. (2008). The antidepressant fluoxetine restores plasticity in the adult visual cortex. Science 320, 385-388.

Mazurek, B., Haupt, H., Joachim, R., Klapp, B. F., Stover, T., and Szczepek, A. J. (2010). Stress induces transient auditory hypersensitivity in rats. Hear. Res. 259, 55-63.

Mello, C. V., and Ribeiro, S. (1998). ZENK protein regulation by song in the brain of songbirds. J. Comp. Neurol. 393, 426-438.

Metzger, R. R., Greene, N. T., Porter, K. K., and Groh, J. M. (2006). Effects of reward and behavioral context on neural activity in the primate inferior colliculus. J. Neurosci. 26 7468-7476.

Miko, I. J., and Sanes, D. H. (2009). Transient gain adjustment in the inferior colliculus is serotonin- and calcium-dependent. Hear. Res. 251, 39-50.

Milbrandt, J. C., Holder, T. M., Wilson, M. C., Salvi, R. J., and Caspary D. M. (2000). GAD levels and muscimol binding in rat inferior colliculus following acoustic trauma. Hear. Res. 147, 251-260.

Miranda, J. A., and Wilczynski, W. (2009a). Female reproductive state influences the auditory midbrain response. J. Comp. Physiol. A Neuroethol. Sens. Neural. Behav Physiol. 195, 341-349.

Miranda, J. A., and Wilczynski, W. (2009b). Sex differences and androgen influences on midbrain auditory thresholds in the green treefrog, Hyla cinerea. Hear. Res. 252, 79-88.

Miyazaki, K. W., Miyazaki, K., and Doya, K. (2011). Activation of the central serotonergic system in response to delayed but not omitted rewards. Eur. J. Neurosci. 33, 153-160.

Morales, M., and Bloom, F. E. (1997). The 5-HT3 receptor is present in different subpopulations of
GABAergic neurons in the rat telencephalon. J. Neurosci. 17, 3157-3167.

Motts, S. D., and Schofield, B. R. (2009). Sources of cholinergic input to the inferior colliculus. Neuroscience 160, 103-114.

Motts, S. D., and Schofield, B. R. (2011). Cholinergic cells in the tegmentum send branching projections to the inferior colliculus and the medial geniculate body. Neuroscience 179, 120-130.

Oertel, D., Wright, S., Cao, X. J., Ferragamo, M., and Bal, R. (2011). The multiple functions of $\mathrm{T}$ stellate/multipolar/chopper cells in the ventral cochlear nucleus. Hear. Res. 276, 61-69.

Okuhara, D. Y., and Beck, S. G. (1994). 5-HT1A receptor linked to inward-rectifying potassium current in hippocampal CA3 pyramida cells. J. Neurophysiol. 71, 2161-2167.

Oliver, D. L., Winer, J. A., Beckius, G. E., and Saint Marie, R. L. (1994). Morphology of GABAergic neurons in the inferior colliculus of the cat J. Comp. Neurol. 340, 27-42.

Palombi, P. S., and Caspary, D. M. (1996). GABA inputs control discharge rate primarily within frequency receptive fields of inferior colliculus neurons. J. Neurophysiol. $75,2211-2219$

Papesh, M. A., and Hurley, L. M. (2012). Plasticity of serotonergic innervation of the inferior colliculus in mice following acoustic trauma. Hear. Res. 283, 89-97.

Peruzzi, D., and Dut, A. (2004). GABA, serotonin and serotonin receptors in the rat inferior colliculus. Brain Res. 998, 247-250

Peyron, C., Petit, J. M., Rampon, C., Jouvet, M., and Luppi, P. H. (1998). Forebrain afferents to the rat dorsal raphe nucleus demonstrated by retrograde and anterograde tracing methods. Neuroscience 82, $443-468$.

Pincherli Castellanos, T. A., Aitoubah, J., Molotchnikoff, S., Lepore, F., and Guillemot, J. P. (2007). Responses of inferior collicular cells to speciesspecific vocalizations in normal and enucleated rats. Exp. Brain Res. 183, 341-350.

Pollak, G. D., Burger, R. M., Park, T. J., Klug, A., and Bauer, E. E. (2002). Roles of inhibition for transforming binaural properties in the brainstem auditory system. Hear. Res. $168,60-78$

Pollak, G. D., Xie, R., Gittelman, J. X., Andoni, S., and Li, N. (2011). The dominance of inhibition in the inferior colliculus. Hear. Res. 274 27-39. 
Polter, A. M., and Li, X. H. (2010). 5-HT1A receptor-regulated signal transduction pathways in brain. Cell. Signal. 22, 1406-1412.

Pompeiano, M., Palacios, J. M., and Mengod, G. (1992). Distribution and cellular localization of mRNA coding for 5-HT1A receptor in the rat brain: correlation with receptor binding. J. Neurosci. 12, 440-453.

Portas, C. M., Bjorvatn, B., and Ursin, R. (2000). Serotonin and the sleep/wake cycle: special emphasis on microdialysis studies. Prog. Neurobiol. 60, 13-35.

Ramsey, L. C., Sinha, S. R., and Hurley, L. M. (2010). 5-HT1A and 5-HT1B receptors differentially modulate rate and timing of auditory responses in the mouse inferior colliculus. Eur. J. Neurosci. 32, 368-379.

Revelis, J., Thompson, A. M., Britton, B. H., and Thompson, G. C. (1998). Effects of para-chlorophenylalanine (pCPA) on the bush baby auditory brainstem response. Hear. Res. 116, 119-130.

Roberts, R. C., and Ribak, C. E. (1987). GABAergic neurons and axon terminals in the brainstem auditory nuclei of the gerbil. J. Comp. Neurol. 258, 267-280.

Salvi, R. J., Saunders, S. S., Gratton, M. A., Arehole, S., and Powers, N. (1990). Enhanced evoked response amplitudes in the inferior colliculus of the chinchilla following acoustic trauma. Hear. Res. 50, 245-257.

Salvi, R. J., Wang, J., and Ding, D. (2000). Auditory plasticity and hyperactivity following cochlear damage. Hear. Res. 147, 261-274.

Sanchez, J. T., Gans, D., and Wenstrup, J. J. (2007). Contribution of NMDA and AMPA receptors to temporal patterning of auditory responses in the inferior colliculus. J. Neurosci. 27, 1954-1963.

Sari, Y. (2004). Serotonin1B receptors: from protein to physiological function and behavior. Neurosci. Biobehav. Rev. 28, 565-582.

Schneider, D. M., and Woolley, S. M. (2010). Discrimination of communication vocalizations by single neurons and groups of neurons in the auditory midbrain. J. Neurophysiol. 103, 3248-3265.

Schneider, D. M., and Woolley, S. M. (2011). Extra-classical tuning predicts stimulus-dependent receptive fields in auditory neurons. J. Neurosci. 31, 11867-11878.

Schofield, B. R., and Coomes, D. L. (2006). Pathways from auditory cortex to the cochlear nucleus in guinea pigs. Hear. Res. 216-217, 81-89.

Shim, H. J., Lee, L. H., Huh, Y., Lee, S. Y., and Yeo, S. G. (2012). Age-related changes in the expression of NMDA, serotonin, and GAD in the central auditory system of the rat. Acta Otolaryngol. 132, 44-50.

Shneiderman, A., Chase, M. B., Rockwood, J. M., Benson, C. G., and Potashner, S. J. (1993). Evidence for a GABAergic projection from the dorsal nucleus of the lateral lemniscus to the inferior colliculus. J. Neurochem. 60 , 72-82.

Shneiderman, A., and Oliver, D. L. (1989). EM autoradiographic study of the projections from the dorsal nucleus of the lateral lemniscus: a possible source of inhibitory inputs to the inferior colliculus. J. Comp. Neurol. 286, 28-47.

Shneiderman, A., Oliver, D. L., and Henkel, C. K. (1988). Connections of the dorsal nucleus of the lateral lemniscus: an inhibitory parallel pathway in the ascending auditory system? J. Comp. Neurol. 276, 188-208.

Smiley, J. F., and Goldmanrakic, P. S. (1996). Serotonergic axons in monkey prefrontal cerebral cortex synapse predominantly on interneurons as demonstrated by serial section electron microscopy. J. Comp. Neurol. 367, 431-443.

Stanford, I. M., and Lacey, M. G. (1996). Differential actions of serotonin, mediated by 5 -HT1B and 5-HT2C receptors, on GABAmediated synaptic input to rat substantia nigra pars reticulata neurons in vitro. J. Neurosci. 16, 7566-7573.

Suta, D., Popelar, J., Kvasnak, E., and Syka, J. (2007). Representation of species-specific vocalizations in the medial geniculate body of the guinea pig. Exp. Brain Res. 183, 377-388.

Suta, D., Popelar, J., and Syka, J. (2008). Coding of communication calls in the subcortical and cortical structures of the auditory system. Physiol. Res. 57(Suppl. 3), S149-S159.

Szczepaniak, W. S., and Moller, A. R. (1996). Effects of (-)-baclofen, clonazepam, and diazepam on tone exposure-induced hyperexcitability of the inferior colliculus in the rat: possible therapeutic implications for pharmacological management of tinnitus and hyperacusis. Hear. Res. 97, 46-53.
Tadros, S. F., D'souza, M., Zettel, M. L., Zhu, X., Lynch-Erhardt, M., and Frisina, R. D. (2007). Serotonin $2 \mathrm{~B}$ receptor: upregulated with age and hearing loss in mouse auditory system. Neurobiol. Aging 28, 1112-1123.

Thompson, A. M. (2006). "Nonserotonergic" lateral superior olivary neurons of the neonatal mouse contain serotonin. Brain Res. 1122, 122-125.

Thompson, A. M., and Lauder, J. M. (2005). Postnatal expression of the serotonin transporter in auditory brainstem neurons. Dev. Neurosci. 27, 1-12.

Thompson, A. M., and Schofield, B. R. (2000). Afferent projections of the superior olivary complex. Microsc. Res. Tech. 51, 330-354.

Thompson, A. M., and Thompson, G. C. (2009). Serotonin-immunoreactive neurons in the postnatal MAO-A KO mouse lateral superior olive project to the inferior colliculus. Neurosci. Lett. 460, 47-51.

Thompson, G. C., Thompson, A. M. Garrett, K. M., and Britton, B. H. (1994). Serotonin and serotonin receptors in the central auditory system. Otolaryngol. Head Neck Surg. 110, 93-102.

To, Z. P., Bonhaus, D. W., Eglen, R. M., and Jakeman, L. B. (1995) Characterization and distribution of putative 5-ht7 receptors in guineapig brain. Br. J. Pharmacol. 115, 107-116.

Tong, L., Altschuler, R. A., and Holt, A. G. (2005). Tyrosine hydroxylase in rat auditory midbrain: distribution and changes following deafness. Hear. Res. 206, 28-41.

Vater, M., Casseday, J. H., and Covey, E. (1995). Convergence and divergence of ascending binaural and monaural pathways from the superior olives of the mustached bat. J. Comp. Neurol. 351, 632-646.

Waeber, C., Sebben, M., Bockaert, J., and Dumuis, A. (1996). Regional distribution and ontogeny of 5-HT4 binding sites in rat brain. Behav. Brain Res. 73, 259-262.

Wang, H. T., Luo, B., Huang, Y. N. Zhou, K. Q., and Chen, L. (2008). Sodium salicylate suppresses serotonin-induced enhancement of GABAergic spontaneous inhibitory postsynaptic currents in rat inferior colliculus in vitro. Hear. Res. 236, $42-51$.

Winer, J. A. (2006). Decoding the auditory corticofugal systems. Hear. Res. 212, 1-8.

Wisden, W., Laurie, D. J., Monyer, H., and Seeburg, P. H. (1992). The distribution of 13-GABA-A receptor subunit messenger RNAs in the rat brain. 1. Telencephalon, diencephalon, mesencephalon. $J$. Neurosci. 12, 1040-1062.

Woolley, S. M., Gill, P. R., and Theunissen, F. E. (2006). Stimulusdependent auditory tuning results in synchronous population coding of vocalizations in the songbird midbrain. J. Neurosci. 26, 2499-2512.

Wright, D. E., Seroogy, K. B., Lundgren, K. H., Davis, B. M., and Jennes, L. (1995). Comparative localization of serotonin1A, 1C, and 2 receptor subtype mRNAs in rat brain. J. Comp. Neurol. 351, 357-373.

Wynne, B., and Robertson, D. (1996) Localization of dopamine-betahydroxylase-like immunoreactivity in the superior olivary complex of the rat. Audiol. Neurootol. 1, 54-64.

Xiang, Z., and Prince, D. A. (2003). Heterogeneous actions of serotonin on interneurons in rat visual cortex. J. Neurophysiol. 89, 1278-1287.

Xie, R., Meitzen, J., and Pollak, G. D. (2005). Differing roles of inhibition in hierarchical processing of species-specific calls in auditory brainstem nuclei. J. Neurophysiol. 94, 4019-4037.

Yang, L., Pollak, G. D., and Resler, C. (1992). GABAergic circuits sharpen tuning curves and modify response properties in the mustache bat inferior colliculus. J. Neurophysiol. 68, 1760-1774

Yavuzoglu, A., Schofield, B. R., and Wenstrup, J. J. (2010). Substrates of auditory frequency integration in a nucleus of the lateral lemniscus. Neuroscience 169, 906-919.

Yavuzoglu, A., Schofield, B. R., and Wenstrup, J. J. (2011). Circuitry underlying spectrotemporal integration in the auditory midbrain. J. Neurosci. 31, 14424-14435.

Ye, Y., and Kim, D. O. (2001). Connections between the dorsal raphe nucleus and a hindbrain region consisting of the cochlear nucleus and neighboring structures. Acta Otolaryngol. 121, 284-288.

Yigit, M., Keipert, C., and Backus, K. H. (2003). Muscarinic acetylcholine receptors potentiate the GABAergic transmission in the developing rat inferior colliculus. Neuropharmacology 45, 504-513.

Zeng, S., Li, J., Zhang, X., and Zuo, M. (2007). Distinction of neurochemistry between the cores and their 
shells of auditory nuclei in tetrapod species. Brain. Behav. Evol. 70, $1-20$.

Zhang, D. X., Li, L., Kelly, J. B., and Wu, S. H. (1998). GABAergic projections from the lateral lemniscus to the inferior colliculus of the rat. Hear. Res. 117, 1-12.

Zhou, F. M., and Hablitz, J. J. (1999). Activation of serotonin receptors modulates synaptic transmission in rat cerebral cortex. J. Neurophysiol. 82, 2989-2999.

Zhou, J., and Shore, S. (2006). Convergence of spinal trigeminal and cochlear nucleus projections in the inferior colliculus of the guinea pig. J. Comp. Neurol. 495, 100-112.

Conflict of Interest Statement: The authors declare that the research was conducted in the absence of any commercial or financial relationships that could be construed as a potential conflict of interest.

Received: 30 April 2012; accepted: 10 August 2012; published online: 06 September 2012.

Citation: Hurley LM and Sullivan MR (2012) From behavioral context to receptors: serotonergic modulatory pathways in the IC. Front. Neural Circuits 6:58. doi: 10.3389/fncir.2012.00058

Copyright (c) 2012 Hurley and Sullivan. This is an open-access article distributed under the terms of the Creative Commons Attribution License, which permits use, distribution and reproduction in other forums, provided the original authors and source are credited and subject to any copyright notices concerning any third-party graphics etc. 